\title{
Regulation of Neuronal Growth Cone Filopodia by Intracellular Calcium
}

\author{
Vincent Rehder and S. B. Kater \\ Department of Anatomy and Neurobiology, Colorado State University, Fort Collins, Colorado 80523
}

\begin{abstract}
Filopodia have been regarded as the sensory extensions of neuronal growth cones. As such, filopodia assay distant environments and are important for directing growth cones toward their targets. Since the territory encountered by a growth cone depends on the area spanned by the filopodia, changes in filopodial length or number result in the "exploration" of different-sized regions of the environment. The present study tests the potential regulatory role of intracellular calcium levels $\left(\left[\mathrm{Ca}^{2+}\right]_{i}\right)$ on filopodial morphology in identified neurons from the snail Helisoma. Experimentally evoked changes in $\left[\mathrm{Ca}^{2+}\right]_{i}$ were measured with the fluorescent calcium indicator fura-2 and directly correlated with growth cone filopodial morphology. A rise in $\left[\mathrm{Ca}^{2+}\right]_{i}$ caused two distinct, concentration-dependent effects separable by their different time courses: within the first $\mathbf{1 0}$ min, filopodia underwent significant elongation, while the second phase was characterized by a massive loss of filopodia. Both of these behaviors were increased in a calcium-dependent fashion. The magnitude of both filopodial elongation and filopodial loss correlated well with the transient peak values of $\left[\mathrm{Ca}^{2+}\right]_{1}$ reached during a given experimental treatment ( $r \leq 0.98$ ). In addition to the direct effect of the initial transient rise in $\left[\mathrm{Ca}^{2+}\right]_{n}$ there is evidence for a form of adaptation of filopodial behavior to sustained calcium levels. A transient change in $\left[\mathrm{Ca}^{2+}\right]_{i}$ of as little as 30-50 $\mathrm{nm}$ reliably altered filopodial morphology. These results indicate that even small changes in intrinsic calcium homeostatic properties or extrinsic signals that alter intracellular calcium levels can act as regulators of the size of the environment sampled by an elongating growth cone.
\end{abstract}

During development neuronal growth cones traverse a complex environment to arrive at their final target. The prominent filopodia on growth cones are typically arranged in a fanlike fashion and have been proposed to play a role as chemical and tactile probes of the environment on the basis of experiments performed both in vivo and in vitro (Harrison, 1910; Nakai and Kawasaki, 1959; Sperry, 1963; Bentley and Toroian-Raymond,

Received Oct. 10, 1991; revised Feb. 28, 1992; accepted Mar. 17, 1992.

We thank Drs. P. Dou and J. R. Jensen for help with the experiments; Drs. R. Davenport, P. B. Guthric, C. McCaig, and L. R. Mills for helpful comments on the manuscript; D. Giddings for help preparing the figures; and Dr. J. R. Zum Brunnen from the Statistics Department at Colorado State University for help with the statistical analysis. This work was supported by NIH Grants NS24683 and NS15350. V.R. was supported by a stipend from the Deutsche Forschungsgemeinschaft $(\operatorname{Re} 722 / 1-1)$.

Correspondence should be addressed to Dr. Vincent Rehder, Department of Anatomy and Neurobiology, Colorado State University, Fort Collins, CO 80523.

Copyright $(C) 1992$ Society for Neuroscience 0270-6474/92/123175-12\$05.00/0
1986; Hammarback and Letourneau, 1986; Bandtlow et al., 1990). This fanlike filopodial configuration may allow a growth cone to cover a vastly enhanced "search" area, as compared to the body of the growth cone itself, and would enhance the likelihood of encountering relevant environmental cues.

Available evidence suggests that filopodia are important in directing outgrowth in vitro (Letourneau, 1979; Bray and Chapman, 1985; Hammarback and Letourneau, 1986; Goldberg and Burmeister, 1989) and possibly for steering in response to guidance cucs in vivo (Bentlcy and Keshishian, 1982; Taghert et al., 1982; Bentley and Toroian-Raymond, 1986; O'Connor et al., 1990). An example of the functional importance of growth cone filopodia is provided by the in vivo preparation of the grasshopper limb bud. Bentley and Toroian-Raymond (1986) observed that growth cones devoid of filopodia continued to grow, though often along aberrant routes, suggesting a loss of steering capability. Filopodia in this system can have a length exceeding $50 \mu \mathrm{m}$ and may physically bridge the distance between different guidepost cells, thereby possibly causing redirection of growth during pathfinding (Ho and Goodman, 1982; Taghert et al., 1982; Bentley and Caudy, 1983; O'Connor et al., 1990). Another example of the functional importance of filopodia in vivo was reported by Bandtlow et al. (1990). Video time-lapse studies of dorsal root ganglion (DRG) growth cones revealed that the contact of a single filopodium with a mature oligodendrocyte was sufficient to trigger arrest and often collapse of the growth cone. A striking example of the guiding role of filopodia comes from Hammarback and Letourneau (1986), who demonstrated that growth cones in vitro could quickly traverse a gap of low-adhesivity substrate when this gap was spanned by even a single filopodium establishing contact on a distant high-adhesivity substrate. In such cases, information obtained by a single filopodium could result in a redirection of growth.

Studies in vivo (Roberts and Taylor, 1983; Taylor and Roberts, 1983; Tosney and Landmesser, 1985; Caudy and Bentley, 1986) and in vitro (Ludueña, 1973; Letourneau, 1979; Bray and Chapman, 1985) convincingly demonstrate that the shape of growth cones and its number of filopodia depend on the environment they traverse, with growth cones exhibiting a more complicated morphology at "decision points" (Taghert et al., 1982; Raper et al., 1983; Tosney and Landmesser, 1985; Eisen et al., 1986; Holt, 1989). On the basis of such evidence, it seems plausible that physiological control over the number of filopodia, as well as filopodial length, could allow a growth cone to sample information from different-sized regions of the environment. In fact, a variety of stimuli have been shown to modify filopodial number and length. Using a simplified model system in vitro, Gundersen and Barrett (1980) reported that the number 
of filopodia increases on the side of a localized application of NGF. A rise in cAMP induced by forskolin can cause a reduction in filopodial number and growth rate (Mattson et al., 1988a). Electric DC fields, applied across growth cones, cause growth toward the cathode (Jaffe and Poo, 1979; McCaig, 1986, 1989), with a higher density of filopodia directed toward the cathode than the anode (McCaig, 1986).

With the large growth cones of neurons from the snail Helisoma, it has been possible to analyze not only the environmental messengers altering growth cone behavior, but also the role of the second messenger calcium. Application of 5-HT was shown to cause a neuron-specific withdrawal of filopodia and, ultimately, cessation of outgrowth (Haydon et al., 1984). 5-HT was then demonstrated to bring about its effects through a rise in intracellular calcium (Cohan et al., 1987). Direct application of the calcium ionophore A23187, qualitatively, was also reported to induce filopodial loss (Mattson and Kater, 1987). Additionally, changes in growth rates and in filopodial numbers were also evoked by electrical stimulation (Cohan and Kater, 1986; Cohan, 1990), a treatment known to raise the intracellular calcium concentration (Cohan et al., 1987). Taken together, these earlier studies proposed a link between a rise in intracellular calcium and the status of filopodia. The present study provides a quantitative analysis of the relationship of intracellular calcium and filopodial behavior and reveals three new aspects of the control of growth cone filopodia. In a dose-dependent fashion, a rise in intracellular calcium is related to the following, sequentially occurring, highly stereotyped, behaviors: (1) filopodial elongation, (2) filopodial loss, and (3) filopodial adaptation. This series of events could significantly affect the sensory capabilities of neuronal growth cones.

\section{Materials and Methods}

Establishing cultures of identified neurons. Adult snails of an inbred laboratory stock of the snail Helisoma trivolvis were used for all experiments (Haydon et al., 1985; Kater and Mattson, 1988). Buccal ganglia were dissected, and identified neurons B5 were individually removed and plated onto polylysine (MW, 70-150 K; Sigma, St. Louis, MO)coated glass coverslip-bottomed cell culture dishes (Falcon 1008, 35 $\mathrm{mm}$ ). Neurons were grown in defined medium consisting of half-strength Leibovitz L- 15 from which all inorganic salts were deleted (special order, GIBCO, Grand Island, NY). Salts were subsequently added to a final concentration of $40 \mathrm{~mm} \mathrm{NaCl}, 1.7 \mathrm{~mm} \mathrm{KCl}, 1.5 \mathrm{~mm} \mathrm{MgCl}, 4.1 \mathrm{~mm}$ $\mathrm{CaCl}_{2}, 5 \mathrm{~mm}$ HEPES, $50 \mu \mathrm{g} / \mathrm{ml}$ gentamycin, and $0.15 \mathrm{mg} / \mathrm{ml}$ glutamine, pH 7.3, in distilled water. Cell culture dishes contained $1 \mathrm{ml}$ of conditioned medium to promote neurite outgrowth (Wong et al., 1981, 1984). Neuronal cultures were kept in a humidified chamber at room temperature $\left(18-22^{\circ} \mathrm{C}\right)$ and were used $20-26 \mathrm{hr}$ after plating in order to obtain growth cones of comparable age and size that exhibited mature veils and filopodia.

Treatment of neuronal cultures. To alter intracellular calcium levels within neurons, the following substances and media were employed. (1) Calcium-free medium contained the concentrations given for defined medium above except that $\mathrm{MgCl}_{2}$ was substituted for $\mathrm{CaCl}_{2}$ and $0.5 \mathrm{~mm}$ EGTA was added. (2) To depolarize neurons, media of varying extracellular potassium concentrations $(8.5 \mathrm{~mm}, 17 \mathrm{~mm}$, and $34 \mathrm{~mm})$ were made by substituting $\mathrm{KCl}$ for $\mathrm{NaCl}(8.5$ and $17 \mathrm{mM})$ or by adding an additional $17 \mathrm{~mm} \mathrm{KCl}$ to the $17 \mathrm{~mm}$ medium to obtain $34 \mathrm{~mm} \mathrm{KCl}$. A full substitution of $34 \mathrm{~mm} \mathrm{KCl}$ for $\mathrm{NaCl}$ would have led to a substantial reduction in $\mathrm{NaCl}(6 \mathrm{~mm})$ and was therefore avoided. To test for possible osmotic effects introduced by the addition of $17 \mathrm{~mm} \mathrm{KCl}$, controls were performed introducing additions of $17 \mathrm{~mm} \mathrm{NaCl}$ or $34 \mathrm{~mm}$ sucrose. These additions had an effect neither on $\left[\mathrm{Ca}^{2+}\right]_{i}$ nor on the filopodial number (not shown). (3) The calcium ionophore 4-bromo A23187 (Molecular Probes, Eugene, OR) was dissolved in dimethyl sulfoxide (DMSO; Aldrich, Milwaukee, WI) as a $0.1 \mathrm{~mm}$ stock solution. The ionophore was added in $15 \mu \mathrm{l}$ volumes to the periphery of a $2 \mathrm{ml}$ medium-con- taining dish to obtain a final concentration of $0.75 \mu \mathrm{M}$ ionophore. The medium subsequently was mixed by gentle agitation with a Pasteur pipette. To test for possible effects of the carrier, $15 \mu 1$ of DMSO $(0.75 \%$ final concentration) were added to the dish in identical manner as the ionophore. Administration of the carrier alone had no effect on $\left[\mathrm{Ca}^{2+}\right]_{i}$ or the number of filopodia. Medium changes were performed by carefully removing all medium from the dish, except from the center coverslip well, which contained about $200 \mu \mathrm{l}$ of medium. New medium was introduced with three to four washes. To control for the effect of a medium change on $\left[\mathrm{Ca}^{2+}\right]_{i}$ or the number of filopodia, growth cones growing in normal medium were rinsed four times with normal medium; the medium change alone had no effect on $\left[\mathrm{Ca}^{2+}\right]$, or filopodial number.

Isolation of growth cones. Growth cones were isolated by transecting neurites close to the growth cone proper with a glass micropipette attached to a micromanipulator (see Rehder et al., 1991). Experiments on isolated growth cones were performed $60 \mathrm{~min}$ after transection on neurons that had previously been filled with fura- 2 . This waiting period proved sufficient to allow isolated growth cones to restore their $\left[\mathrm{Ca}^{2+}\right]_{i}$ to stable values after the transient transection-induced increase.

Calcium measurements. Somata of neurons were filled by microelectrode impalement with fura-2 pentapotassium salt $\left(10 \mathrm{~mm}\right.$ in $\mathrm{H}_{2} \mathrm{O}$; Molecular Probes) by iontophoresis and used 45-60 min after the injection. The distribution of free intracellular calcium within a growth cone before and after treatments was homogeneous with this method of loading. Therefore, calcium measurements were representatively taken from the central region of the growth conc. Cultures were vicwed with an intensified CCD camera (Quantex, Santa Clara, CA) on an inverted microscope (Zeiss, ICM 405 ; Nikon Fluor $40 \times / 1.3$ oil objective). The camera output was digitized with a QX7-210 image processing system (Quantex) and converted into a $640 \times 480$ pixel image. Images taken at two different excitation wavelengths $(350 \pm 10 \mathrm{~nm}$ and $380 \pm 10$ $\mathrm{nm}$ interference filters) were each averaged for 16 frames $(540 \mathrm{msec})$. The fluorescence emission was filtered with a $495 \mathrm{~nm}$ long-pass emission filter. Depending on the brightness of the signal, neutral density filters were used in the excitation pathway to minimize bleaching of the dye and damage to the cell. The ratio $(R)$ of the fluorescence intensity of the two images taken at $350 \mathrm{~nm}$ and $380 \mathrm{~nm}$ was converted to obtain an estimation of calcium concentrations using the formula $\left[\mathrm{Ca}^{2+}\right]_{i}=$ $K_{d}\left[\left(R-R_{\min }\right) /\left(R_{\max }-R\right)\right]\left(F_{0} / F_{s}\right)$ according to Grynkiewicz et al. (1985). The values determined for our system are: $R_{\min }, 0.48 ; R_{\max }, 13.25 ; F_{o}$ ' $F_{s}, 10 ; K_{d}, 224$.

Data acquisition and statistics. Analysis of filopodial behavior was performed on unloaded neurons, and correlated to $\left[\mathrm{Ca}^{2+}\right]_{\text {, obtained from }}$ parallel experiments on fura-2 loaded neurons. This approach was taken in order to eliminate two potential complications: the introduction of a calcium buffer into the neuron, and the possibly adverse effects of repeated illumination of fura- 2 during imaging of filopodial behavior. As many as 20 repeated viewings of fura-2 loaded cells had no effect on levels of intracellular calcium. To assess filopodial numbers, $35 \mathrm{~mm}$ negatives of growth cones were taken through a $40 \times$ objective (Zeiss, Neofluar 40/0.75) on an inverted microscope (Zeiss ICM 405) prior to the treatment and at defined intervals thereafter. Negatives were viewed by projection and filopodia counted for each growth cone and time point. Since filopodial number depends, in part, on the size of a growth cone, a quantification by the criterion "number of filopodia/growth cone" would be strongly biased if a range of growth cones of different sizes were to be used. We therefore normalized the filopodia number to percentage of control. In control experiments, this value was assessed before and after $1 \mathrm{hr}$ of control growth and found to be not significantly different, indicating that growth cones over this time interval did not grow larger and did not develop more filopodia. Only those growth cones that did not branch or fasciculate with other neurites during the experiment were used. Filopodial length was assessed by digitizing phasecontrast images of growth cones on a computer (Macintosh IIx) and using the software package IMAGE (W. Rasband, NIH). For this purpose, the length of all filopodia on a given growth cone was measured, regardless of whether these were extending, retracting, or not changing at all. Normalized dala from growth cones were pooled, and expressed as mean \pm SEM. Both the total number of growth cones and the number of cells used for each experiment are provided in the text. Since the number of growth cones $(n)$ at different time points varied in some experiments due to missing values, $n$ is given as, for example, $n=21-$ 26 (indicating that at least 21 growth cones were measured at all time points and up to 26 at some time points). Overall differences between groups were determined performing an analysis of variance employing 


\section{$17 \mathrm{mM} \mathrm{KCL}$}

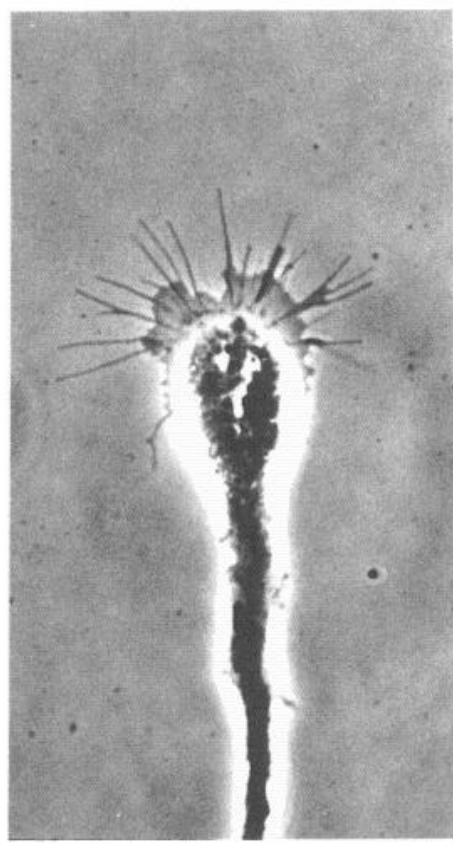

Pre

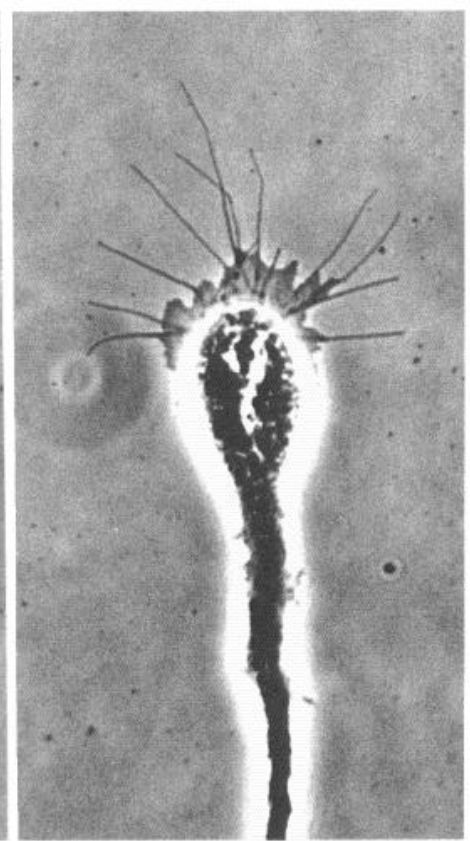

10
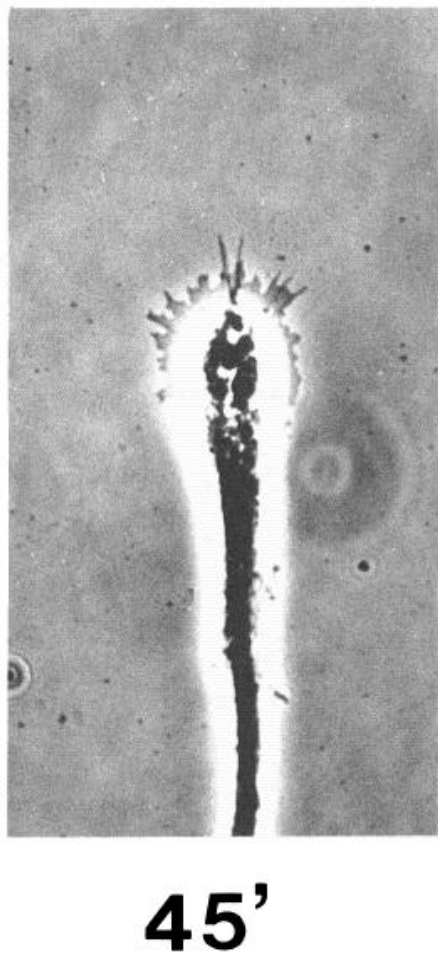

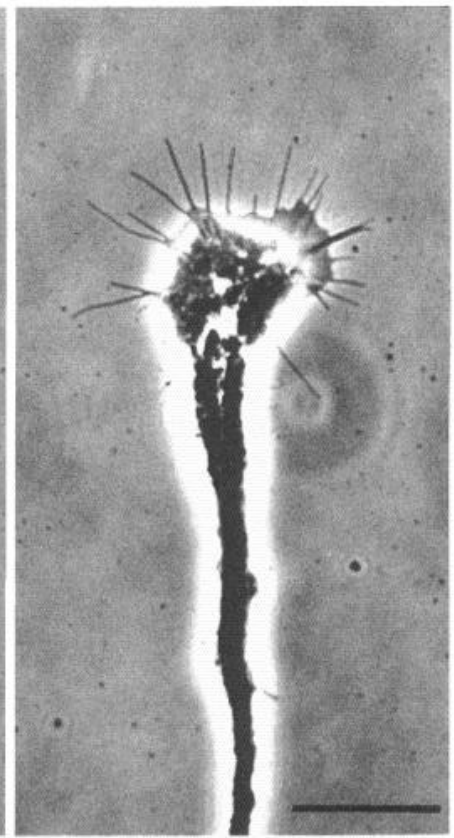

Post wash 30 '

Figure 1. Phase-contrast micrographs demonstrating the effect of a 10 -fold elevation of extracellular [ $\left.\mathrm{K}^{+}\right]$(from 1.7 to $17 \mathrm{~mm}$ ) on filopodial length and filopodial number. Growth cones of a neuron B5 display numerous filopodia and fully developed veil prior to the treatment (Pre). Within the first $10 \mathrm{~min}$, several filopodia elongated significantly $\left(10^{\prime}\right)$. In a second phase, filopodia shortened and many were lost $\left(45^{\prime}\right)$. Return to normal medium completely reversed these effects: the lamellipodium reappeared, new filopodia were generated, and the filopodial number reached pretreatment levels (Postwash $30^{\prime}$ ). The bar indicates the presence of elevated $\left[\mathrm{K}^{+}\right]_{o}$. Scale bar, $20 \mu \mathrm{m}$.

the procedure GLM (General Linear Models) implemented in the statistical package sAS (version 6.04; SAS Institute, Inc, Cary, NC). A specialized $t$ test (LSD, an option in the GLM procedure of SAS), which controls for the comparison-wise error, was employed for subsequent tests of statistical significance. Correlation coefficients were computed using the software package KALEIDAGRAPH, version 2.0 (Synergy Software, Reading, PA).

\section{Results}

Growth cone behavior is undoubtedly derived from the composite activities of many separate underlying processes. This poses significant experimental challenges in relating calcium changes to changes in growth cone behavior. Some of these processes may well be modified by intracellular calcium signals, while others may be independent of this second messenger system. The present study was designed to minimize the experimentally confounding effects of this complexity by focusing on a quantitative description of one discrete component of growth cone behavior, the behavior of the actin-based filopodia. While neurite elongation in Helisoma neurons B5 is very slow (ranging from 10 to $20 \mu \mathrm{m} / \mathrm{hr}$ ), filopodial behavior changes on a time scale comparable to the changes in $\left[\mathrm{Ca}^{2+}\right]_{i}$ experimentally evoked. In the following experiments, $\left[\mathrm{Ca}^{2+}\right]_{i}$ was perturbed and simultaneously measured with the calcium indicator fura- 2 . To avoid any potentially interacting calcium-buffering effects of fura-2, the morphology of filopodia was assessed in an identical experiment on unloaded growth cones and then directly correlated with the observed changes in $\left[\mathrm{Ca}^{2+}\right]_{i}$. This focus on a single component of growth cone behavior undoubtedly accounts for the tight correlation that was ultimately found with altering calcium levels.

\section{Experimental modification of filopodial length and number}

In the first series of experiments, the extracellular potassium concentration $\left(\left[\mathrm{K}^{+}\right]_{o}\right)$ was raised 10 -fold (from the normal concentration of $1.7 \mathrm{~mm}$ to $17 \mathrm{~mm}$ ) with the logic that elevation of $\left[\mathrm{K}^{+}\right]_{o}$ would depolarize neurons and, in turn, open voltage-dependent calcium channels (see next section). Growth cone morphology underwent a stepwise series of distinct changes following this treatment. In a first phase of response, lasting from 2 to $10 \mathrm{~min}$, some filopodia gradually elongated two- to threefold (Fig. 1). The second phase, partially overlapping with the first phase, was characterized by a massive loss of filopodia. Filopodial loss was readily reversible by returning to normal medium $(1.7 \mathrm{~mm} \mathrm{KCl})$, after which filopodia quickly reappeared. The experiments below partition these two phases of filopodial 


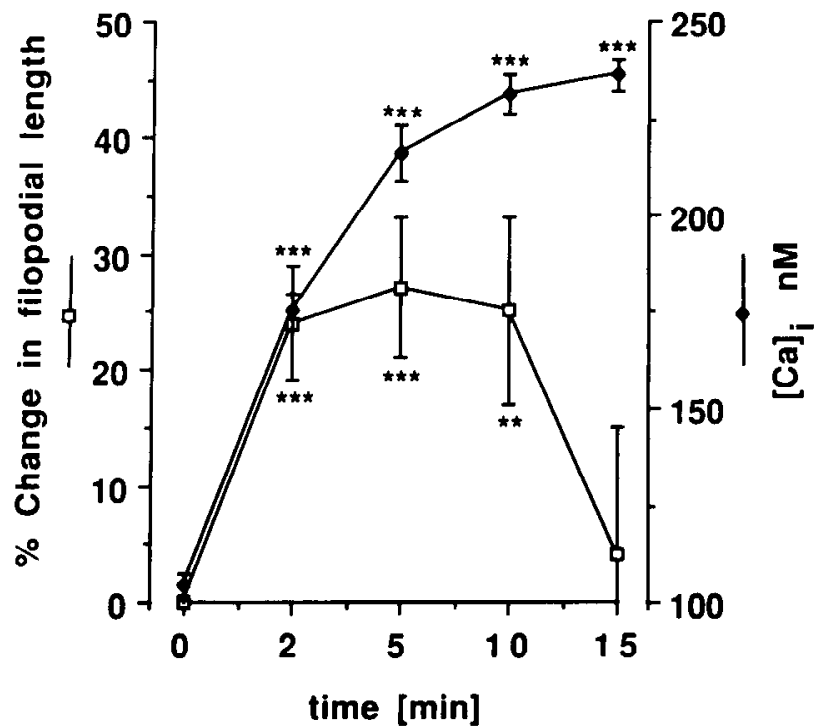

Figure 2. Short-term effects of a 10-fold elevation of extracellar $\left[\mathrm{K}^{+}\right]$ on estimated levels of $\left[\mathrm{Ca}^{2+}\right]_{i}$ and growth cone filopodial length. Elevation of $\left[\mathrm{K}^{+}\right]_{0}$ resulted in a rise in $\left[\mathrm{Ca}^{2+}\right]$, from pretreatment levels of $104 \pm 3$ nм ( $n=48-54$ growth cones of nine neurons) to peak values of $236 \pm 5 \mathrm{~nm}$ within $15 \mathrm{~min}(p<0.001)$. Filopodia displayed a marked, but transient, elongation from pretreatment levels (normalized, $0 \%$ ) for $\sim 10 \mathrm{~min}$ (by $27 \%$ at $5 \mathrm{~min} ; 21-26$ growth cones, $p<0.001$ ) in response to a 10 -fold rise in $\left[\mathrm{K}^{+}\right]_{\text {. }}$. After this elongation, filopodial length returned to pretreatment levels. Note the short time course of elongation in comparison to the longer-lasting effect on filopodial loss shown in Figure $3 b$. Significance levels: ${ }^{* *}, p<0.01 ;^{* * *}, p<0.001$ compared to pretreatment levels.

response and directly assess the effect of elevated $\left[\mathrm{K}^{+}\right]_{o}$ on measured levels of intracellular calcium.

\section{A rise in $\left[\mathrm{Ca}^{2+}\right]_{\mathrm{i}}$ precedes flopodial elongation}

We obtained fura- 2 measurements of $\left[\mathrm{Ca}^{2+}\right]_{i}$ in response to a 10 -fold increase in $\left[\mathrm{K}^{+}\right]_{0}:\left[\mathrm{Ca}^{2+}\right]_{i}$ slowly increased from basal levels of $104 \pm 3 \mathrm{~nm}$ to reach $175 \pm 5 \mathrm{~nm}(n-48-54$ growth cones from nine neurons; $p<0.001$ ) after $2 \mathrm{~min}$ and peak levels of $236 \pm 5 \mathrm{nM}$ after $15 \mathrm{~min}$ (Fig. 2). These changes in $\left[\mathrm{Ca}^{2+}\right]_{i}$ were tightly correlated in time with the initial morphological effect of raised $\mathrm{KCl}$, the elongation of filopodia. The mean filopodial length was significantly increased by $2 \mathrm{~min}$ after the start of the $\mathrm{KCl}$ exposure, reaching a maximum extension of $27 \pm$ $6 \%(n=21-26, p<0.001$ compared to pretreatment $)$ at $5 \mathrm{~min}$ (Fig. 2). The effect on elongation was over after $15 \mathrm{~min}$, though $\left[\mathrm{Ca}^{2+}\right]_{i}$ was still at its maximum. There is an apparent overlap with the second phase of the response, the massive shortening and loss of filopodia, with this initial elongation. This is evident from the fact that net elongation is rather small (27\%) even though individual filopodia elongate by as much as $200-300 \%$. On a given growth cone, one observes concomitant elongation of some and shortening of other filopodia.

To test whether the transient effect on filopodial elongation was dependent on calcium influx, the preceding experiment was repeated in calcium-free medium containing $17 \mathrm{~mm} \mathrm{KCl}$, thereby allowing depolarization but preventing the influx of calcium. This treatment produced no significant rise in $\left[\mathrm{Ca}^{2+}\right]_{i}(n=12$ 25 growth cones of four neurons) within $45 \mathrm{~min}$. Moreover, filopodial length remained unchanged for the initial $10 \mathrm{~min}$, in which filopodial elongation had taken place in the previous experiment. There was, however, a significant decrease in filo- podial length at $15 \min (n=23, p=0.004)$. This reduction in filopodial length could be a result of the lack of extracellular calcium in the medium, a treatment known to transiently decrease $\left[\mathrm{Ca}^{2+}\right]_{i}$ by $16 \%$ (Rehder et al., 1991). We therefore next tested whether the exposure to a calcium-free medium alone would have an effect on filopodial length. This treatment also failed to trigger filopodial elongation but led to a decrease in length at $10 \mathrm{~min}$ and $15 \mathrm{~min}(n=14, p=0.006$ at $15 \mathrm{~min})$ compared to pretreatment length; the values at both time points, however, were not significantly different from the conditions in calcium-free medium plus $17 \mathrm{mM} \mathrm{KCl}$. The decrease seen in calcium-free medium plus $17 \mathrm{~mm} \mathrm{KCl}$, therefore, can be attributed to the calcium-free condition alone. These results suggest that the initial effect seen on elongation of filopodial length is a depolarization-evoked, calcium-dependent phenomenon.

\section{A rise in $[\text { Ca] }]_{i}$ precedes filopodial loss}

The second phase of behavioral change evoked by raising $\left[\mathrm{K}^{+}\right]_{\text {。 }}$ was the loss of filopodia (Fig. 1). This effect, however, although initially overlapping with filopodial elongation, was longer lasting and required observation periods up to $2 \mathrm{hr}$. After a 10-fold increase in extracellular potassium, $\left[\mathrm{Ca}^{2}{ }^{2}\right]_{i}$ increased from basal levels to reach peak levels after $15 \mathrm{~min}$, as previously described. From this time on, $\left[\mathrm{Ca}^{2+}\right]_{i}$ decreased to establish a new plateau value of around $180 \mathrm{~nm}$ for the remainder of the $2 \mathrm{hr}$ observation period (Fig. $3 a$ ). The $\left[\mathrm{Ca}^{2+}\right]_{i}$ remained elevated throughout the $\mathrm{KCl}$ exposure but could be readily reversed by returning to normal ( $1.7 \mathrm{~mm} \mathrm{KCl-containing)} \mathrm{medium.} \mathrm{For} \mathrm{instance,} \mathrm{within}$ $10 \mathrm{~min}$ of restoration to normal $\left[\mathrm{K}^{+}\right]_{o}$, the $\left[\mathrm{Ca}^{2+}\right]_{i}$ had returned to $108 \pm 4 \mathrm{nM}$, a value not significantly different from pretreatment levels.

The potassium-evoked rise in $\left[\mathrm{Ca}^{2+}\right]_{i}$ was closely paralleled in time by a loss of filopodia. Filopodial loss (expressed as percentage loss from pretreatment levels) reached $13 \pm 3 \%$ at 5 min $(n=52-64$ growth cones on nine neurons, $p<0.001)$ and $35 \pm 4 \%$ at $15 \mathrm{~min}$, when the $\left[\mathrm{Ca}^{2+}\right]_{i}$ reached its maximum (Fig. $3 b$ ). Filopodial loss was maximal at $53 \pm 4 \%$ after $30 \mathrm{~min}$, and thereafter the filopodial number remained reduced for another $30 \mathrm{~min}$. It is interesting to note that the loss of filopodia followed the rise in $\left[\mathrm{Ca}^{2+}\right]_{i}$ with a short latency. Growth cones continued to grow in $17 \mathrm{~mm} \mathrm{KCl}$ medium, and naturally occurring branching and fasciculation with other neurites made observations of individual growth cones impossible in the second hour of the observation period. Consequently, growth cone activity could not be quantified for this time interval. After 2 $\mathrm{hr}$, however, growth cones on these neurons looked qualitatively indistinguishable from untreated growth cones. They exhibited a fully developed veil and numerous filopodia despite the continuously elevated levels of $\left[\mathrm{Ca}^{2+}\right]_{i}$, suggesting full filopodial recovery. Experiments described below confirmed this impression: recovery of filopodia took place in $34 \mathrm{~mm} \mathrm{KCl}$ containing medium, where growth was much slower and branching occurred less frequently so that identified growth cones could be observed for the entire duration of the experiment (see beluw).

Calcium influx is the main source of the elevated $\left[\mathrm{Ca}^{2+}\right.$, observed. Repeating the experiment in calcium-free medium containing $17 \mathrm{mM} \mathrm{KCl}$ produced no significant rise in $\left[\mathrm{Ca}^{2+}\right]_{i}$ ( $n=12-25$ growth cones of four neurons; Fig. $3 a$ ). Moreover, filopodial numbers on 35-40 growth cones of four neurons were also not significantly affected by this treatment (Fig. $3 b$ ). Moreover, growth cones ( $n=30$ growth cones of five neurons) displayed no significant change in filopodial number in calcium- 

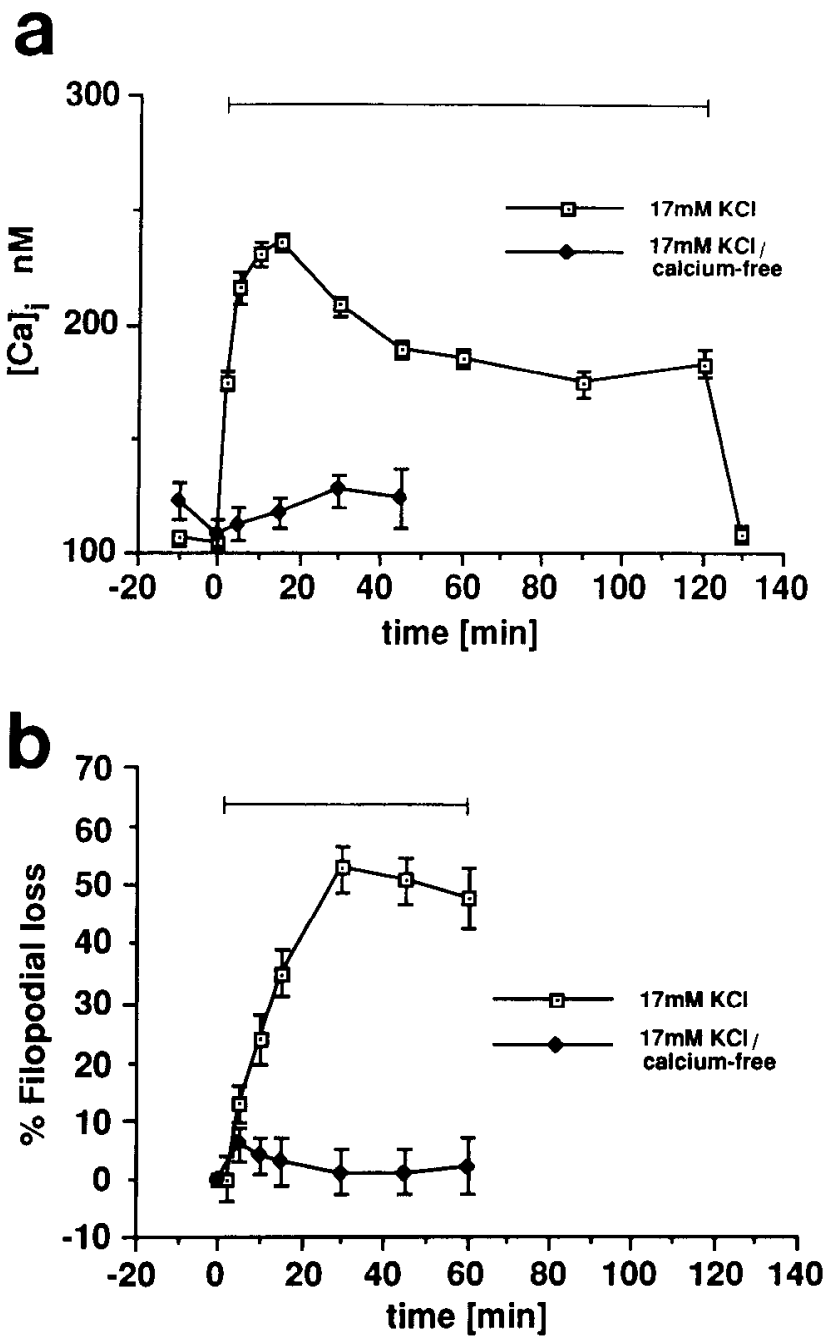

Figure 3. Longer-term effects of a 10-fold elevation of extracellular $\left[\mathrm{K}^{+}\right]$on estimated levels of $\left[\mathrm{Ca}^{2+}\right]_{i}$ and on filopodial number. The bar indicates the presence of elevated $\left[\mathrm{K}^{+}\right]_{o}, a,\left[\mathrm{Ca}^{2+}\right]_{i}$ rose to peak values within $15 \mathrm{~min}$ and thereafter decreased to plateau values of around 180 nM. This level was maintained as long as the $\left[\mathrm{K}^{+}\right]_{\text {。 }}$ remained elevated, but could be rapidly reversed after washout. Raising the $\left[\mathrm{K}^{+}\right]_{o}$ in calciumfree medium did not result in a significant rise in $\left[\mathrm{Ca}^{2+}\right]_{i}(n=12-25$ growth cones of four neurons). $b$, Filopodial loss follows the rise in $\left[\mathrm{Ca}^{2+}\right]_{\text {; }}$ after a short latency. After $15 \mathrm{~min}$, filopodial loss reached $35 \pm$ $4 \%$ (52-64 growth cones of nine neurons, $p<0.001)$, and maximal filopodial loss was reached at $30 \mathrm{~min}(53 \pm 4 \%)$. Filopodial numbers could not be assessed in the second hour of the experiment, because continued growth (branching and fasciculation of growth cones with other neurites) made it impossible to track identified growth cones. Raising the $\left[\mathrm{K}^{+}\right]_{o}$ in calcium-free medium had no effect on filopodial number ( $n=35-40$ growth cones of four neurons).

free medium alone. We therefore conclude that the effect on filopodial loss, as was previously concluded for filopodial elongation, results from a depolarization-induced increase in calcium influx.

\section{Dose dependency of calcium's action on filopodial behavior}

In order to examine more closely the correlation between $\left[\mathrm{Ca}^{2+}\right]_{i}$ and filopodial morphology, we next attempted to generate both smaller or larger rises in $\left[\mathrm{Ca}^{2+}\right]_{i}$ to examine the dose dependency of calcium's action on filopodial behavior. After a small elevation of $\left[\mathrm{K}^{+}\right]_{o}$ (5- instead of 10 -fold), $\left[\mathrm{Ca}^{2+}\right]_{i}$ rose from pretreatment levels of $104 \pm 3 \mathrm{nM}$ ( 33 growth cones of five neurons)
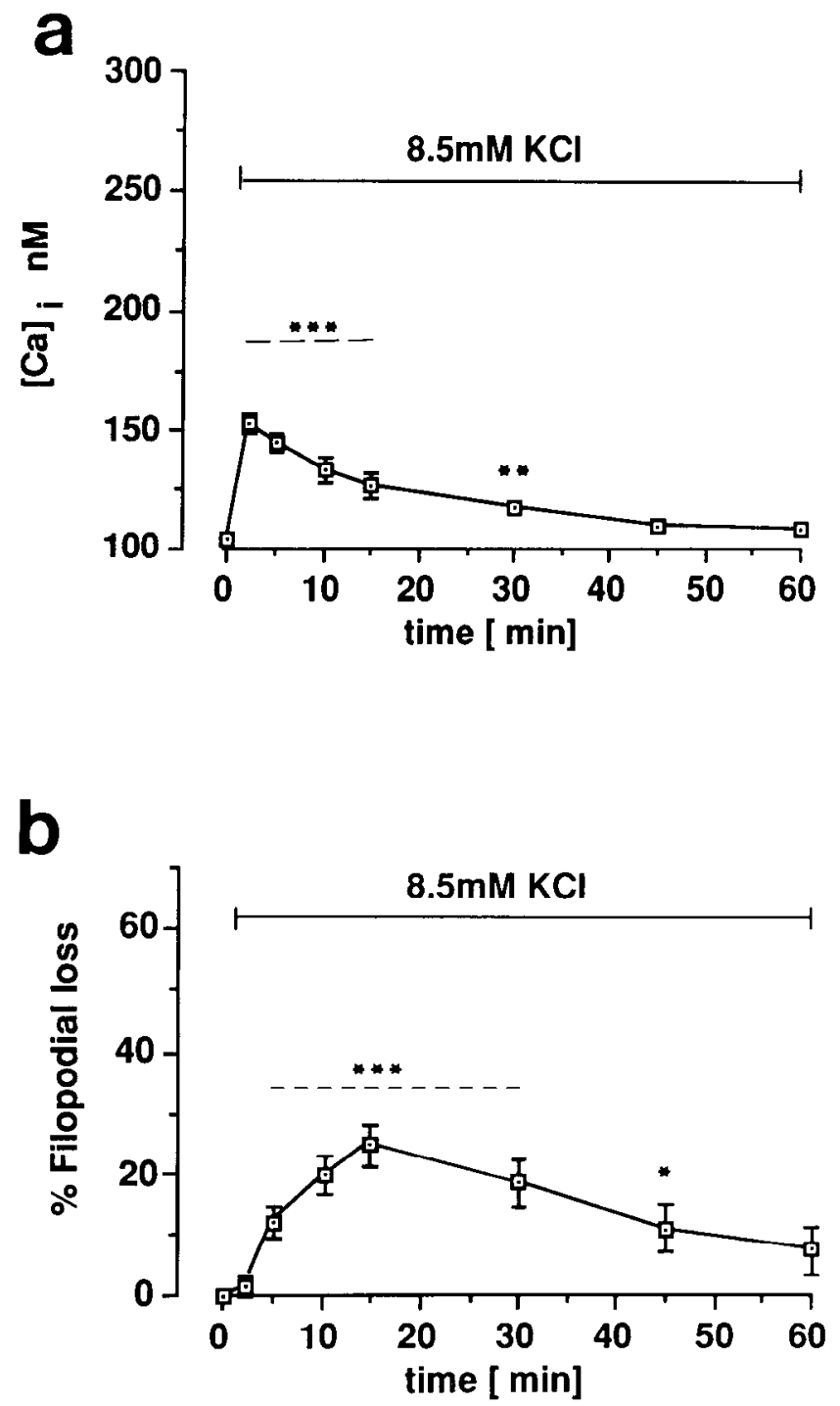

Figure 4. Effect of a fivefold elevation of $\left[\mathrm{K}^{+}\right]_{o}$ on estimated levels of $\left[\mathrm{Ca}^{2+}\right]_{i}$ and on filopodial number. $a$, Upon the change from normal medium to $8.5 \mathrm{mM} \mathrm{KCl},\left[\mathrm{Ca}^{2+}\right]_{i}$ rose from pretreatment levels of 104 \pm 3 ( $n=33$ growth cones of five neurons) to reach its maximum of $152 \pm 4 \mathrm{~nm}(p<0.001)$ at $2 \mathrm{~min}$. Thereafter, $\left[\mathrm{Ca}^{2+}\right]_{i}$ fully recovered within $45 \mathrm{~min} . b$, Corresponding to the smaller rise in $\left[\mathrm{Ca}^{2+}\right]_{i}$ (as compared to the 10 -fold elevation of $\left[\mathrm{K}^{+}\right]_{o}$ in Fig. 3), there was a small filopodial loss that reached $25 \pm 4 \%(n=47$ growth cones of five neurons) and fully recovered within $60 \mathrm{~min}$. Significance levels: ${ }^{*}, p<$ $0.05 ;{ }^{* *}, p<0.01 ;{ }^{* * *}, p<0.001$ compared to pretreatment.

to $152 \pm 4 \mathrm{nM}$ by $2 \min (p<0.001)$, and from thereon decreased to recover fully after $45 \mathrm{~min}$ (Fig. $4 a$ ). This small rise in $\left[\mathrm{Ca}^{2+}\right]_{i}$ of about $50 \mathrm{~nm}$ caused only a small effect on filopodia. Filopodial elongation (phase 1) was statistically significant, however, from controls at the $5 \mathrm{~min}$ time point, when it reached $9 \pm 4 \%(n=$ 17 growth cones of six neurons, $p<0.05$ ). Filopodial number (phase 2), however, was reduced by $12 \pm 3 \%(n=47$ growth cones of five neurons, $p<0.001)$ at $5 \mathrm{~min}$ and exhibited its strongest effect of $25 \pm 4 \%$ at $15 \mathrm{~min}$ (Fig. $4 b$ ). Thereafter, filopodial loss was reversed and recovery was complete at 60 min. A smaller depolarization, therefore, had only a transient effect on $\left[\mathrm{Ca}^{2+}\right]_{i}$ and both filopodial length and number.

Raising $\left[\mathrm{K}^{+}\right]_{o} 20$-fold (from 1.7 to $34 \mathrm{~mm}$ ) led to a greater rise in $\left[\mathrm{Ca}^{2+}\right]_{i}$ and had an increased effect on the filopodia. $\left[\mathrm{Ca}^{2+}\right]_{i}$ 

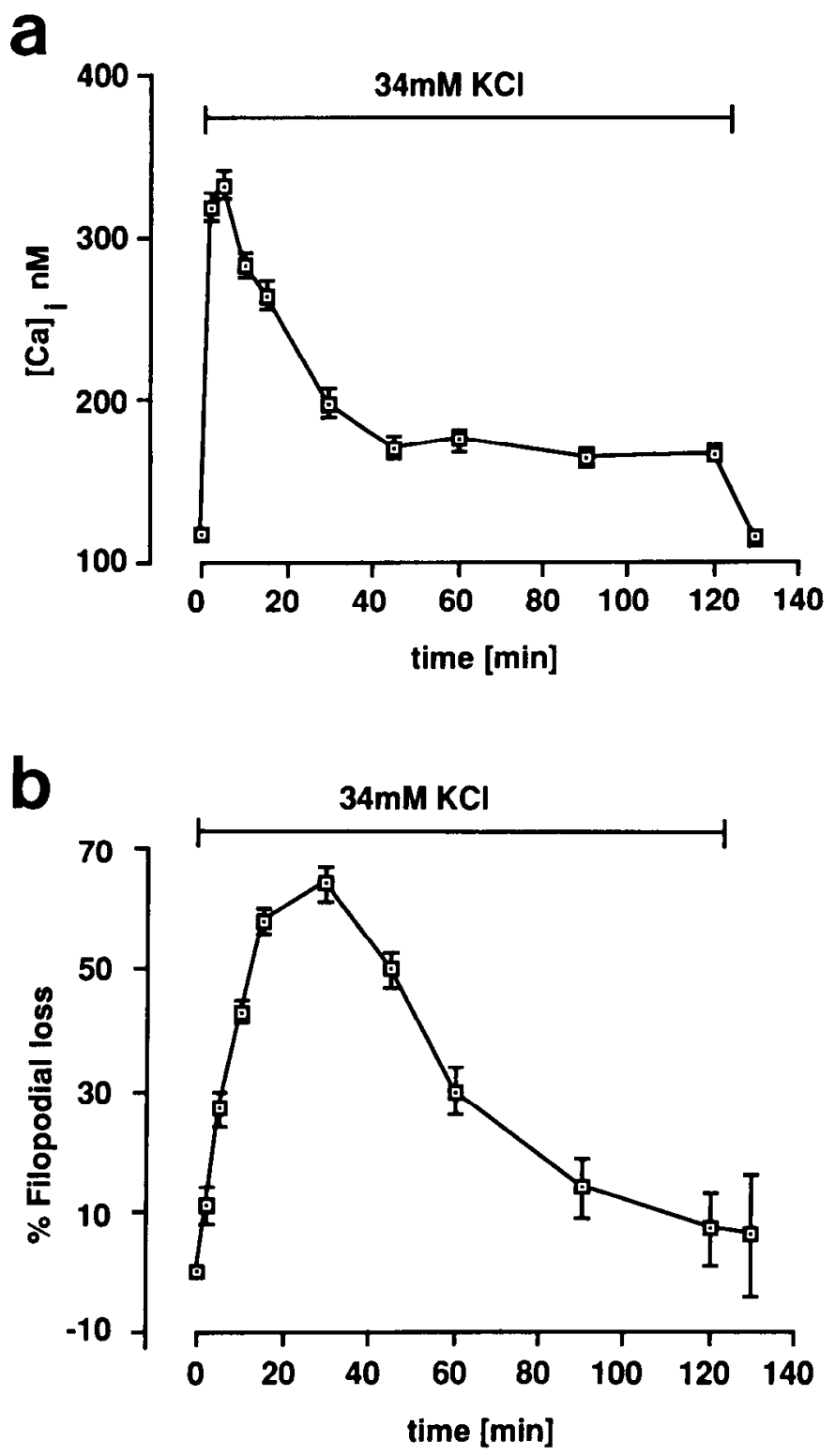

Figure 5. Effect of a 20 -fold elevation of $\left[\mathrm{K}^{+}\right]_{o}$ (from 1.7 to $34 \mathrm{~mm}$ ) on estimated levels of $\left[\mathrm{Ca}^{2+}\right]_{i}$ and on filopodial number. $a$, This elevation of $\left[\mathrm{K}^{+}\right]_{o}$ resulted in $\left[\mathrm{Ca}^{2+}\right]_{i}$ rising more quickly than seen previously and also reached higher values $(334 \pm 9 \mathrm{nM} ; n=25-51$ growth cones of seven neurons, $p<0.001$ ). From peak levels, $\left[\mathrm{Ca}^{2+}\right]_{i}$ decreased to a plateau of around $180 \mathrm{~nm}$. $b$, Filopodial loss was more pronounced under these conditions, compared to previous treatments. At $5 \mathrm{~min}$, filopodial loss had already reached $27 \pm 3 \%(n=43-71$ growth cones of six neurons, $p<0.001$ ) and maximal filopodial loss was $64 \pm 3 \%$ at $30 \mathrm{~min}$. Interestingly, filopodial numbers thereafter recovered to pretreatment levels within $120 \mathrm{~min}$, despite the fact that $\left[\mathrm{Ca}^{2+}\right]_{i}$ was still significantly elevated at a plateau of around $180 \mathrm{nM}$.

rapidly rose from basal levels of $117 \pm 3 \mathrm{~nm}$ to $320 \pm 9 \mathrm{~nm}$ at 2 min ( $n=25-51$ growth cones of seven neurons, $p<0.001$ ) and reached peak levels of $334 \pm 9 \mathrm{~nm}$ at $5 \mathrm{~min}$. Thereafter, $\left[\mathrm{Ca}^{2+}\right]_{i}$ gradually decreased to a plateau of about $180 \mathrm{nM}$, which was maintained as long as the $\left[\mathrm{K}^{+}\right]_{\text {o }}$ remained elevated (Fig. $5 a$ ). Filopodial elongation (phase 1) was observed throughout the first $10 \mathrm{~min}$, as was the case in $17 \mathrm{mM} \mathrm{KCl}$ medium, and reached a maximum of $41 \pm 11 \%$ over controls $(n=21$ growth cones of five neurons, $p=0.001$ ). Filopodial loss (phase 2), in turn, reached $11 \pm 3 \%$ after $2 \mathrm{~min}(n=43-71$ growth cones from six neurons, $p<0.001), 43 \pm 2 \%$ after $10 \mathrm{~min}$, and increased to reach its maximum of $64 \pm 3 \%$ at $30 \mathrm{~min}$ (Fig. $5 b$ ). From this time, filopodial number steadily recovered and reached pretreatment levels after $120 \mathrm{~min}$ in the continuous presence of elevated $\left[\mathrm{K}^{+}\right]_{o}$. Filopodial recovery took place while the $\left[\mathrm{Ca}^{2+}\right]_{\iota}$ was still elevated. Thus, for pragmatic purposes, one might consider that in addition to the two effects on filopodial behavior demonstrated so far, there exists a third phase in response 10 the evoked rise in $\left[\mathrm{Ca}^{2+}\right]_{i}$, namely, filopodial "adaptation" to sustained elevations of $\left[\mathrm{Ca}^{2+}\right]_{i}$.

A second perturbation that did not depend on the activation of voltage-gated calcium channels was also employed to increase $\left[\mathrm{Ca}^{2+}\right]_{i}$ in growth cones. The calcium ionophore 4-bromo A23187 $(0.75 \mu \mathrm{M})$ was recently shown to raise $\left[\mathrm{Ca}^{2+}\right]_{i}$ in growth cones in this system (Rehder et al., 1991). The effect on filopodial number is shown in micrographs in Figure $6 a$ and quantitatively expressed in Figure $7 b$. $\Lambda$ fter application of ionophore, $\left[\mathrm{Ca}^{2+}\right]_{i}$ was elevated from rest levels of $135 \pm 2 \mathrm{~nm}$ to $459 \pm 36 \mathrm{~nm}$ ( 57 growth cones from seven neurons, $p<0.001$ ) within $5 \mathrm{~min}$, whereupon $\left[\mathrm{Ca}^{2+}\right]_{i}$ decreased to a plateau around $260 \mathrm{nM}$ (Rehder et al., 1991; Fig. 7a). Filopodial elongation (phase 1) was prominent between 5 and $30 \mathrm{~min}$ and reached maximal levels of $45 \pm 11 \%$ after $15 \mathrm{~min}$ ( $n=15$ growth cones of four neurons). Five minutes after application of the ionophore, the number of filopodia (phase 2) was dramatically reduced by $53 \pm 3 \%$ of pretreatment levels ( $n=46$ growth cones of six neurons, $p<$ 0.001 ), reaching its maximal loss of $72 \pm 4 \%$ at $15 \mathrm{~min}$ (Fig. $7 b$ ). However, despite the continuous presence of the ionophore, the number of filopodia was restored to pretreatment levels within $60 \mathrm{~min}$, indicating filopodial "adaptation" (phase 3) to sustained elevations of $\left[\mathrm{Ca}^{2+}\right]_{i}$, as was the case with $34 \mathrm{mM} \mathrm{KCl}$.

A small increase of about $30 \mathrm{~nm}$ in $\left[\mathrm{Ca}^{2+}\right]_{i}$ can be produced by the application of $0.75 \mu \mathrm{M} 4$-bromo $\Lambda 23187$ in a calciumfree medium (Fig. 7a). This rise is likely due to ionophoremediated release from internal stores of calcium, since influx is not possible under this condition (Rehder et al., 1991). Employing this treatment, the filopodial number (phase 2) was reduced by $15 \pm 4 \%$ of controls within $10 \mathrm{~min}(n=16$ growth cones of four neurons, $p=0.005$ ) and thereafter recovered (Fig. 7b). Filopodial length (phase 1) was not assessed in this experiment. This experiment demonstrates that an increase in $\left[\mathrm{Ca}^{2+}\right]_{i}$ of as small as $30 \mathrm{nM}$ can significantly alter filopodial behavior.

\section{Isolated growth cones}

An earlier study demonstrated that growth cones isolated from the remainder of the neuron by neurite transection are capable of controlling their $\left[\mathrm{Ca}^{2+}\right]_{i}$ to a similar degree as growth cones attached to their parent neurons. With this preparation, we determined whether the treatments described above acted directly on the growth cone, or indirectly through the cell body to alter filopodial behavior. Upon transection, $\left[\mathrm{Ca}^{2+}\right]_{i}$ in the isolated growth cone is transiently raised to values exceeding $1000 \mathrm{~nm}$ and quickly restored toward basal levels within $10 \mathrm{~min}$ (Rehder et al., 1991). Interestingly, this rise in $\left[\mathrm{Ca}^{2+}\right]_{i}$, albeit quite transient, was also accompanied by a significant elongation of filopodia that rapidly reached a maximal value of $33 \pm 5 \%$ at 5 $\min (n=19-23, p<0.001)$. The effect on elongation lasted for $10 \mathrm{~min}$.

After $60 \mathrm{~min}$, isolated growth cones appeared normal, with fully developed veils and filopodia (Fig. $6 b$ ). Levels of intracellular calcium were also restored to basal values at this time after transection (Rehder et al., 1991). Isolated growth cones, 

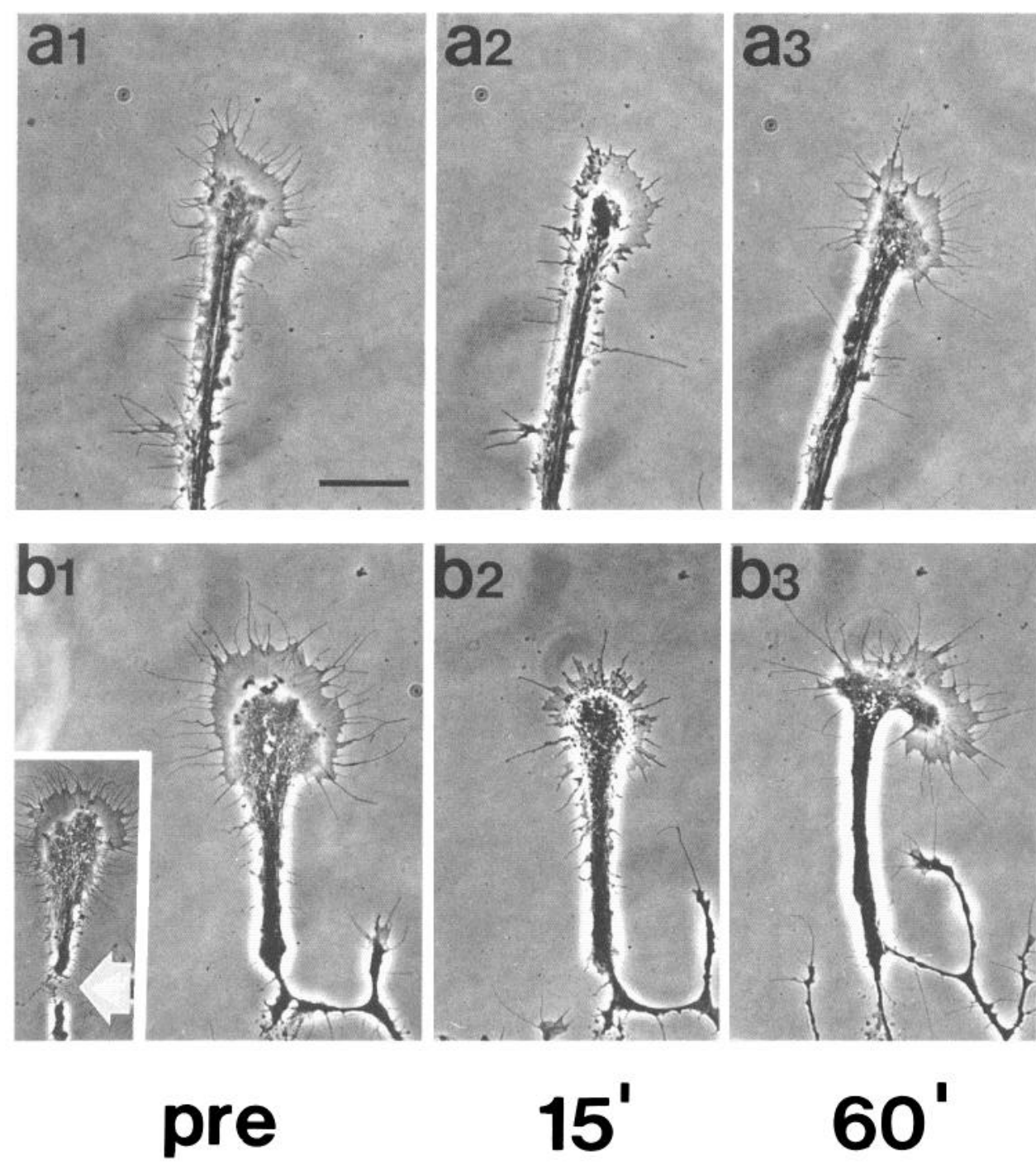

\section{A23187}

Figure 6. Phase-contrast micrographs demonstrating the effects of the calcium ionophore 4-bromo A23187 (0.75 $\mu \mathrm{M})$ on filopodial numbers in attached $(a)$ and isolated $(b)$ growth cones. Note the decrease and subsequent restoration of filopodia before $\left(a_{1}, b_{1}\right)$, at $15 \mathrm{~min}\left(a_{2}\right.$, $b_{2}$ ), and at $60 \mathrm{~min}$ after ionophore treatment $\left(a_{3}, b_{3}\right)$. The inset in $b_{i}$ shows the growth cone demonstrated in $b, 55 \mathrm{~min}$ prior to the experiment, that is, $5 \mathrm{~min}$ after isolation (arrow marks transection site). At later time points $\left(b_{1}-b_{3}\right)$, other growth cones of this neuron contacted the isolated growth cone and partly obscured the fact that it had been previously isolated. Scale bar, $20 \mu \mathrm{m}$. in addition to their ability to display filopodial elongation, also showed filopodial loss upon raising the $\left[\mathrm{K}^{+}\right]_{o}$. After a 10-fold increase in $\left[\mathrm{K}^{+}\right]_{o}$, filopodial loss reached $22 \pm 6 \%(n=39-43$ growth cones of nine neurons) after $10 \mathrm{~min}$, and maximal levels of $79 \pm 6 \%$ at $45 \mathrm{~min}$ (Fig. $8 b$ ). With the same treatment, $\left[\mathrm{Ca}^{2+}\right]_{i}$ rose from pretreatment levels of $136 \pm 4 \mathrm{nM}$ to $274 \pm 9 \mathrm{nM}(n$ $=37-43$ growth cones from nine neurons, $p<0.001)$ after 5 min (Fig. $8 a$ ). From peak values, $\left[\mathrm{Ca}^{2+}\right]_{i}$ decreased to plateau values of around $180 \mathrm{nM}$, as was the case in intact growth cones. As might be expected, essentially identical results were obtained with the ionophore 4-bromo A23187 $(0.75 \mu \mathrm{M})$ on isolated growth cones. This treatment has previously been shown to evoke a substantial rise in $\left[\mathrm{Ca}^{2+}\right]_{i}$ that was very similar to the one seen in attached growth cones (Rehder et al., 1991). Accordingly, filopodial loss reached $20 \pm 6 \%$ of controls in $5 \mathrm{~min}$, and reached its highest level after 30 min with $63 \pm 6 \%(n=23$ growth cones from six neurons). Filopodia were then restored between 30-60 min and reached pretreatment levels after $60 \mathrm{~min}$ (Fig. $6 b$ ), despite elevated levels of intracellular calcium. Thus, iso- lated growth cones were also able to display the third phase of filopodial behavior previously described for attached growth cones, namely, filopodial adaptation. Therefore, local rises of $\left[\mathrm{Ca}^{2+}\right]_{i}$ in the growth cone proper, independent of the treatment used to evoke these rises, can control filopodial behavior.

\section{Correlation between $\left[\mathrm{Ca}^{2+}\right]_{\mathrm{i}}$ and filopodial behavior}

The data provided by the various experiments of this investigation allow one to analyze statistically the relationship between a rise in $\left[\mathrm{Ca}^{2+}\right]_{i}$ and filopodial length and number. The peak values of $\left[\mathrm{Ca}^{2+}\right]_{i}$ reached during the treatments previously described were plotted against the maximal effect observed on filopodial length (Fig. 9a) and filopodial loss (Fig. 9b), thus bringing together the two different types of data from the preceding experiments. With the expectation of a physiological dose-response curve, we approximated the data by a logarithmic function of the form $y=a+b \cdot \log x$. Correlation coefficients of $r=0.99$ and $r=0.98$ were found for calcium and filopodial length and loss, respectively, indeed, suggesting a strong cor- 

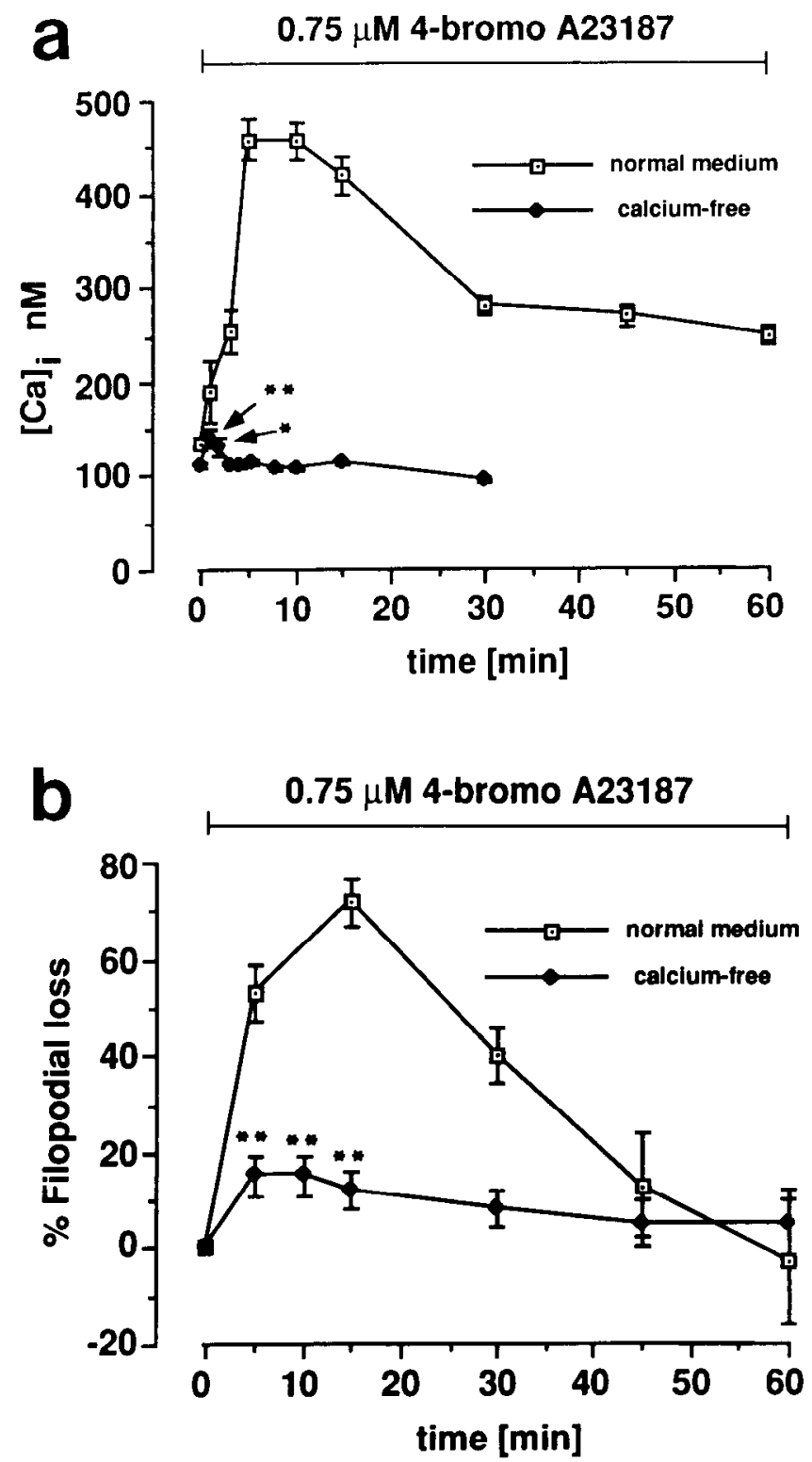

Figure 7. Effect of calcium ionophore 4-bromo A23187 on estimated levels of $\left[\mathrm{Ca}^{2+}\right]$, and on filopodial numbers. $a$, Upon ionophore addition $(0.75 \mu \mathrm{M}),\left[\mathrm{Ca}^{2+}\right]_{i}$ rose from pretreatment levels to $459 \pm 36 \mathrm{nM}$ within $5 \min (n=57$ growth cones of seven neurons) but was restored to a new plateau lcvel of around $260 \mathrm{~nm}$ after $30 \mathrm{~min}$. After addition of the same concentration of ionophore in calcium-free medium, however, $\left[\mathrm{Ca}^{2+}\right]_{i}$ only rose from rest levels of $110 \pm 3 \mathrm{nM}(n=12$ growth cones of two neurons) to $141 \pm 10 \mathrm{nM}$ within the first minute $(p=0.007)$ and thereafter quickly recovered to pretreatment values (data taken from Rehder et al., 1991). $b$, Filopodial numbers were reduced to $53 \pm 3 \%$ ( $n=46$ growth cones of six neurons, $p<0.001$ ) by $5 \mathrm{~min}$, and the maximal loss occurred at $15 \mathrm{~min}(72 \pm 4 \%)$. The filopodia fully recovered within $60 \mathrm{~min}$, despite the elevated values of $\left[\mathrm{Ca}^{2+}\right]_{i}$. Addition of the ionophore in calcium-free medium caused a maximal filopodial loss of $15 \pm 4 \%$ at $5 \mathrm{~min}$ ( $n=16$ growth cones of four neurons). Thereafter, filopodial numbers increased again and were not different from pretreatment levels at 45 min. Significance levels: ${ }^{*}, p<0.05{ }^{* *}, p<0.01$ compared to pretreatment.

relation between the $\left[\mathrm{Ca}^{2+}\right]_{i}$ and both parameters of filopodial behavior. The fact that both data sets ( $\mathrm{KCl}$ and 4-bromo A23187) fit the curve well suggests that it is indeed the rise in $\left[\mathrm{Ca}^{2+}\right]_{i}$ that brings about the effects seen, and that it does not matter by which method this rise is induced. Since the number of filopodia
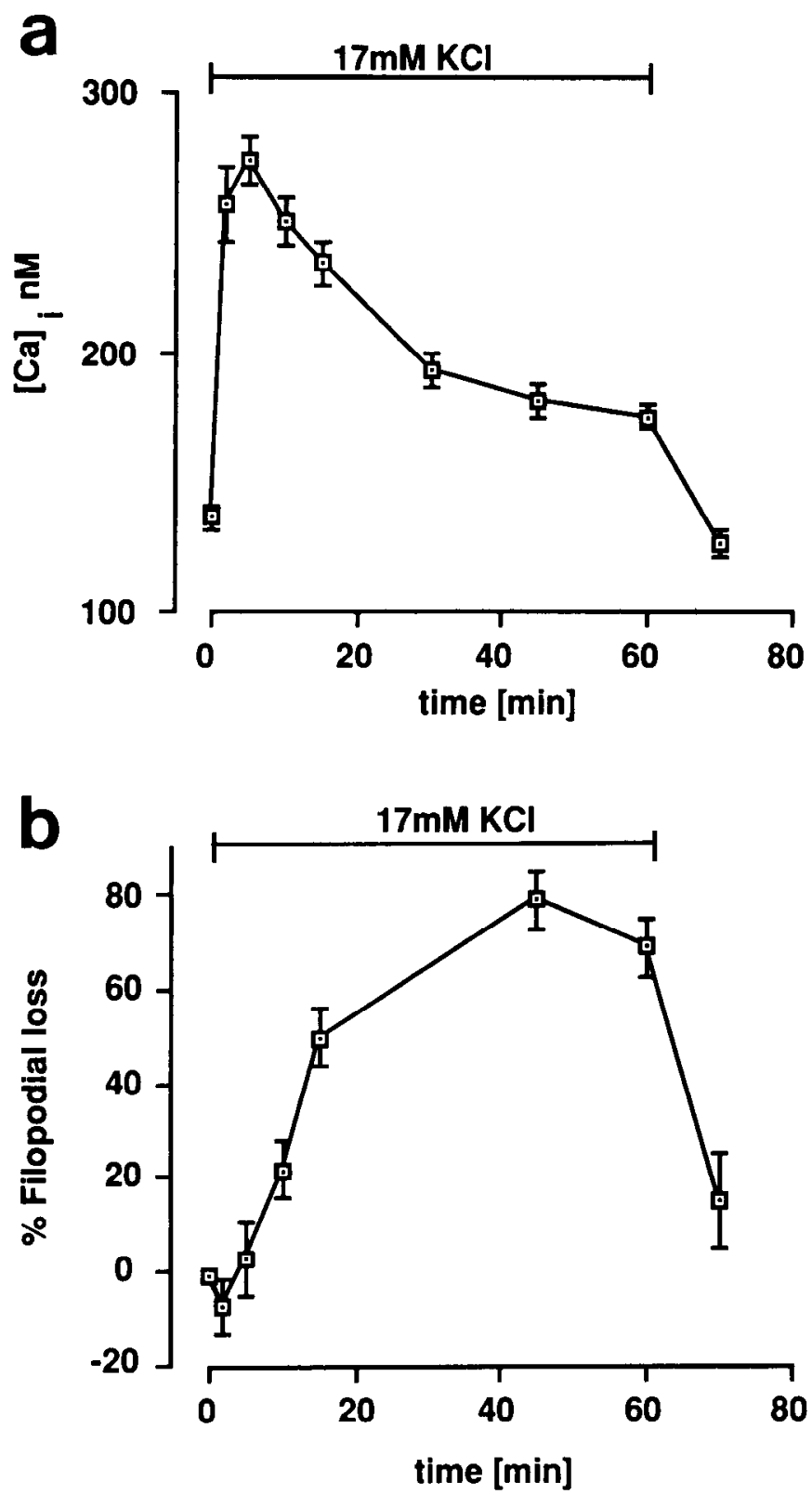

Figure 8. The response of isolated growth cones to a 10-fold elevation of $\left[\mathrm{K}^{+}\right]_{o}$ on estimated levels of $\left[\mathrm{Ca}^{2+}\right]_{i}$ and on filopodial number. $a$, Upon the medium change, $\left[\mathrm{Ca}^{2+}\right]$ rose to peak levels of $274 \pm 9 \mathrm{nM}$ $(n=37-43)$ at $5 \mathrm{~min}$. Thereafter, $\left[\mathrm{Ca}^{2+}\right]_{i}$ steadily decreased to plateau levels of around $180 \mathrm{~nm}$, as was the case in attached growth cones. Upon returning to normal medium, $\left[\mathrm{Ca}^{2+}\right]_{i}$ was reduced to pretreatment levels within $10 \mathrm{~min}$. $b$, Filopodial loss gradually increased and reached maximum levels of $79 \pm 6 \%$ at $45 \mathrm{~min}$ ( $n=39-43$ growth cones). Upon returning to normal, medium filopodia were also quickly restored.

returned to pretreatment values after extended treatment periods, a comparison of plateau levels of $\left[\mathrm{Ca}^{2+}\right]_{i}$ and filopodial loss showed no correlation (correlation coefficient $r=0.2$ ).

\section{Discussion}

Filopodia on neuronal growth cones are thought to be important structures for directing neuronal outgrowth both in vitro (Letourneau, 1979; Bray and Chapman, 1985; Hammarback and Letourneau, 1986; Goldberg and Burmeister, 1989) and in vivo (Bentley and Keshishian, 1982; Taghert et al., 1982; Bentley and Toroian-Raymond, 1986; O'Connor et al., 1990). Time- 

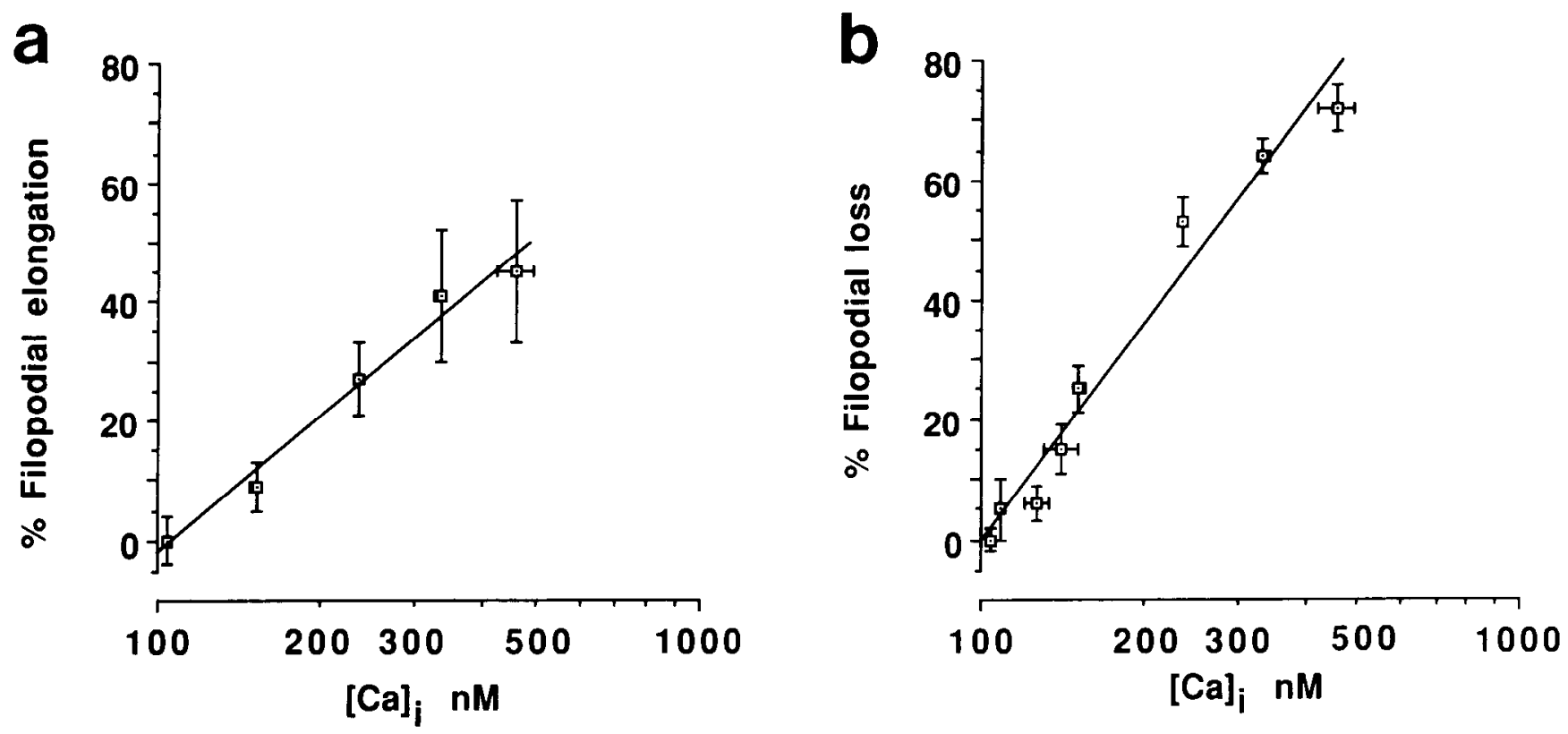

Figure 9. Statistical correlation between estimated $\left[\mathrm{Ca}^{2+}\right]_{i}$ and filopodial length $(a)$ and filopodial loss $(b)$ in attached growth cones. Peak values of $\left[\mathrm{Ca}^{2+}\right]_{i}$ reached during each treatment (for different $\left[\mathrm{K}^{+}\right]_{o}$ and ionophore treatments) were plotted against maximal values of filopodial length (correlation coefficient $r=0.99)$ and filopodial loss $(r=0.98)$, indicating a strong correlation between $\left[\mathrm{Ca}^{2+}\right]_{i}$ and both phases of filopodial behavior. Where error bars are not visible, they are confined in the data point.

lapse studies from a variety of preparations have revealed that filopodia are highly dynamic structures that protrude from the body of the growth cone in a fanlike fashion. Changes in filopodial patterns depend on the molecular terrain the growth cone traverses in vivo (Roberts and Taylor, 1983; Taylor and Roberts, 1983; Tosney and Landmesser, 1985; Caudy and Bentley, 1986), with growth cones exhibiting a more complex morphology often with elongated filopodia at "decision points" encountered along its route (Taghert et al., 1982; Raper et al., 1983; Tosney and Landmesser, 1985; Eisen et al., 1986; Holt, 1989).

\section{Possible significance of filopodial regulation}

Although it is generally accepted that filopodia could play a role in the searching behavior of growth cones, it is worth examining what the advantages of subcellular regulation of filopodial behavior might be. Given the potentially complex nature of the molecular terrain over which neuronal growth cones must traverse, a variety of qualitatively and quantitatively different cues may be encountered, some even simultaneously. It is possible to envision the growth cone traversing terrain that periodically signals the growth cone to alter its "searching behavior" by increasing or decreasing the length and/or number of filopodia. Elongation of filopodia would effectively increase the specific area "surveyed" by the growth cone and potentially affect neuronal guidance. Additionally, rapid elongation would allow a filopodium to bridge distances within minutes, which otherwise would be hours away assuming standard rates of growth cone advance. Alternatively, it is possible to envision the molecular terrain signaling the growth cone to decrease its "searching behavior." In this scenario, one might envision a growth cone elongating in the absence of filopodia as has been shown after application of cytochalasin (Argiro et al., 1984; Marsh and Letourneau, 1984; Bentley and Toroian-Raymond, 1986; Letourneau et al., 1987; McCaig, 1989). Thus, the searching behavior of the growth cone would be decreased and it would be biased toward continuing along an established path, despite potential cues in the surrounding environment. Growth cones of neurons following established tracts or fascicles have indeed been described as being less morphologically complex compared to pioneer neurons (Lopresti et al., 1973; Taylor and Roberts, 1983; Caudy and Bentley, 1986).

An active control of the number and length of filopodia would serve, therefore, an important role in providing the growth cone with an optimal flow of information about its environment. Given the time course of filopodial elongation, a variety of different scenarios is possible. The elongating filopodium could contact an important guiding structure and then be transformed into the future neurite by dilation, thereby laying down the direction of future growth as described for pioneer neurons of the grasshopper (O'Connor et al., 1990). Alternatively, a filopodium could come in contact with its final target and the growth cone could be transformed into a presynaptic structure (Gottlieb and Glaser, 1980; Tsui et al., 1985). In a third scenario, filopodia may not reach a significant signal at all and would subsequently be retracted. Depending on the signal and the way it is translated by the growth cone, environmental cues could then activate the appropriate building blocks of growth cone behavior, such as turning toward or away from a cue, increasing the growth rate or stopping. Taken together, the ability to regulate physiologically the number and length of filopodia on a growth cone, could have great significance for the final processes of neuronal pathfinding and synaptogenesis.

\section{"Behavioral" correlates of changes in $\left[\mathrm{Ca}^{2+}\right]_{i}$}

A large literature exists on the effects of both intra- and extracellular calcium concentrations on growth and motility in neurons (Anglister et al., 1982; Suarez-Isla et al., 1984; Cohan et al., 1987; Mattson and Kater, 1987; Kater et al., 1988; Mattson et al., 1988c; Campenot and Draker, 1989; Robson and Burgoyne, 1989; Silver et al., 1989; Fields et al., 1990a,b; Kater 


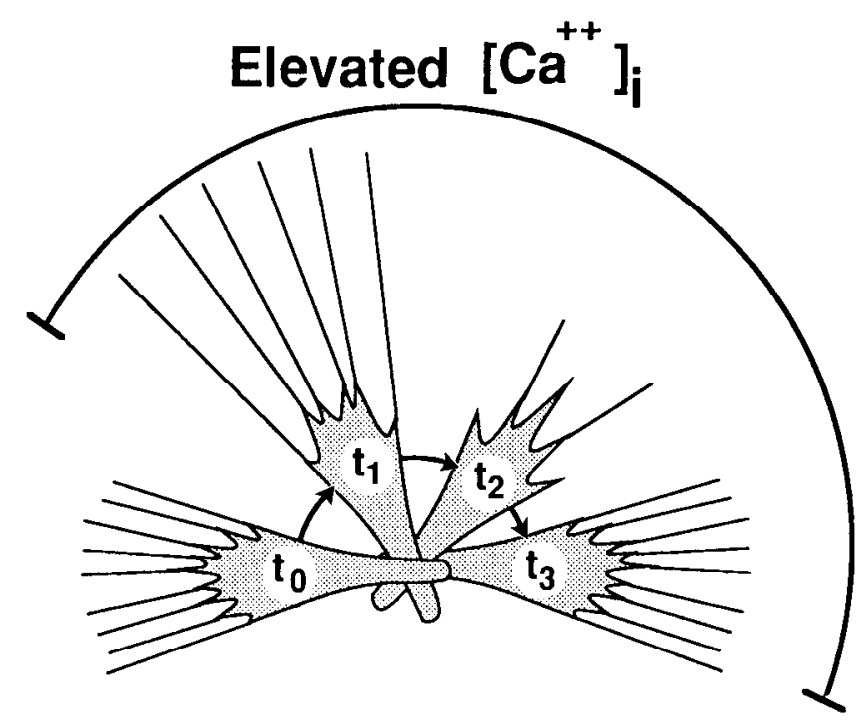

Figure 10. Schematic diagram of three different phases of filopodial behavior sequentially elicited by a constant duration stimulus that evokes an increase in $\left[\mathrm{Ca}^{2+}\right]_{1}$. At basal levels of $\left[\mathrm{Ca}^{2+}\right]_{t}$, growth cones exhibit numerous filopodia $\left(t_{0}\right)$. A rise in $\left[\mathrm{Ca}^{2+}\right]_{i}$ results in a stereotyped series of the following filopodial activities: filopodial elongation $\left(t_{t}\right)$, filopodial loss $\left(t_{2}\right)$, and filopodial adaptation $\left(t_{3}\right)$. The reduction in filopodial number indicated in $t_{t}$ reflects the fact that filopodial loss partially overlaps with filopodial elongation. A potential variation in the tightly locked relationship between flopodial elongation and flopodial loss might occur in vivo, for instance, by spatially and temporally restricted environmental cues evoking only elongation or only filopodial loss, perhaps even by altering filopodial behavior only on one side of the growth cone.

and Mills, 1991; Lankford and Letourneau, 1991). Calcium is strongly implicated in regulating elements of the cytoskeleton and could, by this means, influence neuronal growth (Stossel et al., 1985; Mooseker et al., 1986; Mitchison and Kirschner, 1988; Smith, 1988; Forscher, 1989; Lankford and Letourneau, 1989, 1991; Letourneau and Shattuck, 1989; Bamburg and Bernstein, 1991).

Previous studies of neurite elongation often involved treatments that would alter $\left[\mathrm{Ca}^{2+}\right]_{i}$ with the assumption that these treatments would have sustained effects on $\left[\mathrm{Ca}^{2+}\right]_{i}$. However, recent studies on Helisoma neurons demonstrated that effects on $\left[\mathrm{Ca}^{2+}\right]_{i}$ are often transient, due to the compensatory properties of calcium homeostasis (Rehder et al., 1991). Given the relatively slow nature of growth cone advance in Helisoma and the relatively fast rate of calcium compensatory processes, it is difficult to design investigations that will effectively test for a correlation between outgrowth and $\left[\mathrm{Ca}^{2+}\right]_{i}$. The present study is not limited in the same way since the sensitive filopodial assay allows one to monitor morphological changes on a minuteby-minute time scale, corresponding to the time course of monitored changes in $\left[\mathrm{Ca}^{2+}\right]_{i}$. It should be kept in mind that measurements of filopodial behavior and $\left[\mathrm{Ca}^{2+}\right]_{i}$ were not performed on the same growth cones but on growth cones from parallel cultures. This approach was chosen to eliminate two problems: the introduction of a calcium buffer into a neuron, and the repeated UV illumination of growth cones. Nonetheless, the tight statistical correlation, the close temporal associations, and the control experiments in calcium-free medium clearly speak to a causal role for rises in $\left[\mathrm{Ca}^{2+}\right]_{i}$ mediating these changes in filopodial behavior.

\section{Filopodial elongation and filopodial loss}

Multiple mechanisms may exist for regulating growth cone filopodia. The present investigation demonstrates that one important way to change filopodial disposition is by raising $\left[\mathrm{Ca}^{2+}\right]_{i}$. Elevating the levels of this second messenger has highly predictable effects on both filopodial length and number in a sequential fashion. These results, obtained in both in attached and isolated growth cones, indicate a local control over these components of growth cone behavior. After a rise in $\left[\mathrm{Ca}^{2+}\right]_{i}$, a population of filopodia first extended for approximately $10 \mathrm{~min}$, followed by a massive filopodial loss (Fig. 10). The initial elongation as well as the filopodial loss were calcium dependent since depolarization with $17 \mathrm{mM} \mathrm{KCl}$ in the absence of extracellular calcium failed to produce an effect. It is, therefore, not the depolarization per se, but the rise in $\left[\mathrm{Ca}^{2+}\right]_{i}$ that led to the effects on filopodia. Moreover, both events were strongly correlated with the peak values of $\left[\mathrm{Ca}^{2+}\right]_{i}$ reached during each treatment. These results let us conclude that it is the transient, and not the sustained, increases in $\left[\mathrm{Ca}^{2+}\right]_{i}$ (during which filopodia "adapt" as discussed below) that contain the information responsible for the initial filopodial changes. The correlation data between $\left[\mathrm{Ca}^{2+}\right]_{i}$ and filopodial length and number are best fit by a logarithmic function, suggesting that relatively small increases in $\left[\mathrm{Ca}^{2+}\right]_{i}$ from rest levels can effectively alter the growth cone's cytoskeleton. The smallest rise in $\left[\mathrm{Ca}^{2+}\right]$, that would still significantly affect filopodial behavior was determined to be about $30 \mathrm{nM}$. This increase in $\left[\mathrm{Ca}^{2+}\right]$, was produced when ionophore was administered in the absence of extracellular calcium, thereby eliminating the influx component (Rehder et al., 1991). The origin of calcium in this case is most likely from intracellular stores of calcium.

Increases in $\left[\mathrm{Ca}^{2+}\right]_{i}$ could come about by a variety of stimuli ranging from electrical activity (Cohan et al., 1987) to diffusible or substrate bound environmental cues (Mattson et al., 1988b; Schmidt et al., 1991). In experiments employing Helisoma neurons $\mathrm{B} 19$ and $\mathrm{B} 4$, electrical stimulation, previously shown to elevate $\left[\mathrm{Ca}^{2+}\right]_{i}$ (Cohan et al., 1987), has revealed a graded inhibition of filopodial number and neuronal advance (Cohan, 1990). Mattson and Kater (1987) qualitatively reported results in which they showed a decrease in filopodial number upon application of the nonbrominated A23187. Lankford and Letourneau $(1989,1991)$ showed evidence that calcium can act as a regulator of actin filaments in DRG growth cones. After application of $2.5 \mu \mathrm{M} \mathrm{A} 23187$ on DRG neurons, they showed changes, on the ultrastructural level, in the cytoskeleton, mainly a disruption or destabilization of actin filaments, but of microtubules as well. By setting $\left[\mathrm{Ca}^{2+}\right]_{i}$ in calcium-permeable DRG neurons to predetermined levels, Lankford and Letourneau (1991) demonstrated that growth cone behavior is highly sensitive to changes in $\left[\mathrm{Ca}^{2+}\right]_{i}$ as small as $50 \mathrm{~nm}$. This value is in excellent agreement with the present findings. It is interesting to note, however, that while we find a strong decrease in the number of filopodia, Lankford and Letourneau (1989, 1991) report the main effect on actin filaments to be in the veil and not on filopodia. The difference in sensitivity between the two preparations might be explained by a difference in localization of molecules known to influence the cytoskeleton. For example, a calcium-sensitive form of $\alpha$-actinin has been demonstrated in filopodia of differentiated PC-12 cells, while a calcium-insensitive form is localized in the other parts of the growth cone (Sobue and Kanda, 1989). 
While $\mathrm{KCl}$ depolarization and ionophore treatment employed in this study acted globally on the growth cone as a whole, environmental signals could signal a growth cone to increase its "searching behavior" by selectively sending out individual filopodia in various directions by selectively and transiently raising intracellular calcium levels in discrete regions of the growth cone. The plausibility of such a local stimulus-response system is indicated by the study of local clusters of L-type calcium channels in growth cones of N1E-115 neuroblastoma cells, which can evoke local rises in $\left[\mathrm{Ca}^{2+}\right]_{t}$ (Silver et al., 1990), and by the correlation observed between local filopodial elongation and local calcium influx into growth cones in Helisoma neurons (Davenport and Kater, 1991).

Filopodia contain an actin core and could, therefore, either be directly susceptible to an increase in $\left[\mathrm{Ca}^{2+}\right]_{i}$ or could be indirectly effected by calcium via its action on actin-binding proteins (Mitchison and Kirschner, 1988; Forscher, 1989; Bamburg and Bernstein, 1991). Several proteins known to affect actin have been demonstrated immunocytochemically in neuronal growth cones and filopodia, including cross-linking agents like $\alpha$-actinin (Letourneau and Shattuck, 1989; Sobue and Kanda, 1989), fimbrin (Shaw et al., 1981), and filamin (Letourneau and Shattuck, 1989), as well as membrane-anchoring proteins like integrins, talin, and vinculin (Letourneau and Shatluck, 1989). A calcium-sensitive form of $\alpha$-actinin has been demonstrated in filopodia of differentiated PC-12 cells, while a calcium-insensitive form is localized in the other parts of the growth cone (Sobue and Kanda, 1989). Moreover, actin depolymerizing factor has been demonstrated to be a major component in the growth cone extending into the filopodia (Bamburg and Bernstein, 1991). Profilin, which is thought to regulate the levels of assembled actin, as well as villin and gelsolin are likely candidates involved in the regulation of the actin-based cytoskcleton. The role, however, that these proteins might play, and the way they might interact within the growth cone remain to be understood.

\section{Filopodial adaptation}

Depending on the degree of calcium influx elicited by our treatment, $\left[\mathrm{Ca}^{2+}\right]_{i}$ either returned to basal levels (in the cases of 8.5 $\mathrm{mM} \mathrm{KCl}$ and ionophore in calcium-free medium) or remained elevated at plateaus significantly above baseline levels (in the cases of $17 \mathrm{mM}$ and $34 \mathrm{mM} \mathrm{KCl}$, as well as $0.75 \mu \mathrm{M}$ 4-bromo A23187). These results suggest that calcium homeostatic mechanisms intrinsic to the neuron are able to restore $\left[\mathrm{Ca}^{2+}\right]_{i}$ when the generated influx is small, while a larger influx resulted in an elevated plateau. This elevated plateau indicates an equilibrium between sustained calcium influx through noninactivated calcium- or ionophore channels that cannot bc completely compensated by the calcium clearance mechanisms.

The number of filopodia, however, gradually recovered despite the elevated plateau levels of $\left[\mathrm{Ca}^{2+}\right]_{i}$, indicating that filopodia can "adapt" to elevated $\left[\mathrm{Ca}^{2+}\right]_{i}$ and that there appears to be a wide range of $\left[\mathrm{Ca}^{2+}\right]_{i}$ permissive for normal cytoskeletal organization. This finding indicates that the filopodial number is not determined by the absolute value of intracellular calcium present at any given time, since a rise from basal levels to any of these plateau values would have resulted in a considerable filopodial loss. The significant correlation between the peak values of $\left[\mathrm{Ca}^{2+}\right]$, and the peak values of filopodial loss support the notion that the magnitude of filopodial loss is determined by the magnitude of the initial calcium rise.

\section{Conclusion}

The behavior of growth cones undoubtedly comprises many processes and control systems, each requiring independent investigation. The present study has attempted to dissect these processes by focusing on one aspect of the control of one process by a single second messenger system of the growth cone. The capacity for varying filopodial number and length by altering $\left[\mathrm{Ca}^{2+}\right]_{i}$, together with the previous work on a potential sensorlike role for filopodia, reinforces the idea that these structures may act as telescoping sensory probes for guiding neuronal pathfinding.

\section{References}

Anglister L, Farber I, Shahar A, Grinvald A (1982) Localization of voltage-sensitive calcium channels along developing neurites: their possiblc role in regulating neurite elongation. Dev Biol 94:351-365.

Argiro V, Bunge MB, Johnson MI (1984) Correlation between growth form and movement and their dependence on neuronal age. J Neurosci 4:3051-3062.

Bamburg JR, Bernstein BW (1991) Actin and actin-binding proteins in neurons. In: The neuronal cytoskeleton (Burgoyne RD, ed), pp 121-160. New York: Wiley-Liss.

Bandtlow C, Zachleder T, Schwab ME (1990) Oligodendrocytes arrest neurite growth by contact inhibition. J Neurosci 10:3837-3848.

Bentley D, Caudy M (1983) Pioneer axons lose directed growth after selective killing of guidepost cells. Nature 304:62-65.

Bentley D, Keshishian H (1982) Pathfinding by peripheral pioneer neurons in grasshoppers. Science 218:1082-1088.

Bentley D, Toroian-Raymond A (1986) Disoriented pathfinding by pioneer neurone growth concs deprived of filopodia by cytochalasin treatment. Nature 323:712-715.

Bray D, Chapman K (1985) Analysis of microspike movements of the neuronal growth cone. J Neurosci 5:3204-3213.

Campenot RB, Draker DD (1989) Growth of sympathetic nerve fibers in culture does not require extracellular calcium. Neuron 1:733-743.

Caudy M, Bentley D (1986) Pioneer growth cone morphologies reveal proximal increases in substrate affinity within leg segments of grasshopper embryos. J Neurosci 6:364-379.

Cohan CS (1990) Frequency-dependent and cell-specific effects of electrical activity on growth cone movements of cultured Helisoma neurons. J Neurobiol 21:400-413.

Cohan CS, Kater SB (1986) Suppression of neurite elongation and growth cone motility by electrical activity. Science 232:1638-1640.

Cohan CS, Connor JA, Kater SB (1987) Elcctrically and chemically mediated increases in intracellular calcium in neuronal growth cones. J Neurosci 7:3588-3599.

Davenport RW, Kater SB (1991) Small electric fields alter neuronal growth cone morphology, navigation and cause highly localized intracellular calcium changes. Soc Neurosci Abstr 17:372.4.

Eisen JS, Myers PZ, Westerfield M (1986) Pathway selection by growth cones of identified motoneurones in live zebra fish embryos. Nature 320:269-271.

Fields RD, Guthrie PB, Nelson PG, Kater SB (1990a) Calcium homeostatic capacity is regulated by patterned electrical activity in growth cones of mouse DRG neurons. Soc Neurosci Abstr 16:197.2.

Fields RD, Neale EA, Nelson PG (1990b) Effects of alterned electrical activity on neurite outgrowth from mouse sensory neurons. J Neurosci 10:2950-2964

Forscher P (1989) Calcium and polyphosphoinositide control of cytoskeletal dynamics. Trends Neurosci 12:468-474.

Goldberg DJ, Burmeister DW (1989) Looking into growth cones. Trends Neurosci 12:503-506.

Gottlieb DI, Glaser L (1980) Cellular recognition during neural development. Annu Rev Neurosci 3:303-318.

Grynkiewicz G, Poenie M, Tsien R (1985) A new generation of Ca indicators with greatly improved fluorescence properties. J Biol Chem 260:3440-3450.

Gundersen RW, Barrett JN (1980) Characterization of the turning response of dorsal root neurites towards nerve growth factor. J Cell Biol 87:546-554.

Hammarback JA, Letourneau PC (1986) Neurite extension across 
regions of low cell-substratum adhesivity: implications for the guidepost hypothesis of axonal pathfinding. Dev Biol 117:655-662.

Harrison RG (1910) The outgrowth of the nerve fiber as a mode of protoplasmic movement. J Exp Zool 9:787-848.

Haydon PG, McCobb DP, Kater SB (1984) Serotonin selectively inhibits growth cone motility and the connectivity of identified neurons. Science 226:561-564.

Haydon PG, Cohan CS, McCobb DP, Miller HR, Kater SB (1985) Neuron-specific growth cone properties as seen in identified neurons of Helisoma. J Neurosci Res 13:135-147.

Ho RK, Goodman CS (1982) Peripheral pathways are pioneered by an array of central and peripheral neurones in grasshopper embryos. Nature 297:404-406.

Holt CE (1989) A single-cell analysis of early retinal ganglion cell differentiation in Xenopus: from soma to axon tip. J Neurosci 9:31233145 .

Jaffe LF, Poo MM (1979) Neurons grow faster towards the cathode than the anode in a steady field. J Exp Zool 209:1 15-127.

Kater SB, Mattson MP (1988) Extrinsic and intrinsic regulators of neurite outgrowth and synaptogenesis in isolated, identified Helisoma neurons in culture. In: Cell culture approaches to invertebrate neuroscience (Beadle DJ, Lees G, Kater SB, eds), pp 1-31. New York: Academic.

Kater SB, Mills LR (1991) Regulation of growth cone behavior by calcium. J Neurosci 1 1:891-899.

Kater SB, Mattson MP, Cohan CS, Connor J (1988) Calcium regulation of the neuronal growth cone. Trends Neurosci 11:315-321.

Lankford KL, Letourneau PC (1989) Evidence that calcium may control neurite outgrowth by regulating the stability of actin filaments. J Cell Biol 109:1229-1243.

Lankford KL, Letourneau PC (1991) Roles of actin filaments and three second-messenger systems in short term regulation of chick dorsal root ganglion neurite outgrowth. Cell Motil Cytoskel 20:7-29.

Letourneau PC (1979) Cell-substratum adhesion of neurite growth cones, and its role in neurite elongation. Exp Cell Res 124:127-138.

Letourneau PC, Shattuck TA (1989) Distribution and possible interactions of actin-associated proteins and cell adhesion molecules of nerve growth cones. Development 105:505-519.

Letourneau PC, Shattuck TA, Ressler AH (1987) "Pull" and "push" in neurite elongation: observations on the effect of different concentrations of cytochalasin B and taxol. Cell Motil Cytoskel 8:193-209.

Lopresti V, Macagno ER, Levinthal C (1973) Structure and development of neuronal connections in isogenic organisms: cellular interactions in the development of the optic lamina of Daphnia. Proc Natl Acad Sci USA 70:433-437.

Ludueña MA (1973) The growth of spinal ganglion neurons in serum free medium. Dev Biol 33:470-476.

Marsh L, Letourneau PC (1984) Growth of neurites without filopodial or lamellipodial activity in the presence of cytochalasin B. J Cell Biol 99:2041-2047

Mattson MP, Kater SB (1987) Calcium regulation of neurite elongation and growth cone motility. J Neurosci 7:4034-4043.

Mattson MP, Taylor-Hunter A, Kater SB (1988a) Neurite outgrowth in individual neurons of a neuronal population is differentially regulated by calcium and cyclic AMP. J Neurosci 8:1704-1711.

Mattson MP, Guthrie PB, Kater SB (1988b) Components of neurite outgrowth which determine neuronal architecture: influence of calcium and the growth substrate. J Neurosci Res 20:331-345.

Mattson MP, Guthrie PB, Kater SB (1988c) Intracellular messengers in the gencration and degencration of hippocampal neuroarchitecture. J Neurosci Res 21:447-464.

McCaig CD (1986) Dynamic aspects of amphibian neurite growth and the effects of an applied electric field. J Physiol (Lond) 375:55-69.

McCaig CD (1989) Nerve growth in the absence of growth cone filopodia and the effects of a small applied electric field. J Cell Sci 93: 715-721.

Mitchison T, Kirschner M (1988) Cytoskeletal dynamics and nerve growth. Neuron 1:761-772.

Mooseker MS, Coleman TR, Conzelman KA (1986) Calcium and the regulation of cytoskeletal assembly, structure and contractility. In: Ciba Foundation symposium 122, Calcium and the cell (Evered D, Whelan J, eds), pp 232-249. New York: Wiley.

Nakai J, Kawasaki Y (1959) Studies of the mechanism determining the course of nerve fibers in tissue culture. Z Zellforschung 51:108122.

O'Connor TP, Duerr JS, Bentley D (1990) Pioneer growth cone steering decisions mediated by single filopodial contacts in situ. J Neurosci 10:3935-3946.

Raper JA, Bastiani M, Goodman CS (1983) Pathfinding by neuronal growth cones in grasshopper embryos. I. Divergent choices made by the growth cones of sibling neurons. J Neurosci 3:20-30.

Rehder V, Jensen JR, Dou P, Kater SB (1991) A comparison of calcium homeostasis in isolated and attached growth cones of the snail Helisoma. J Neurobiol 22:499-511.

Roberts A, Taylor JSH (1983) A study of the growth cones of developing embryonic sensory neurites. J Embryol Exp Morphol 75:3147.

Robson SJ, Burgoyne RD (1989) L-type calcium channels in the regulation of neurite outgrowth from rat dorsal root ganglion neurons in culture. Neurosci Lett 104:110-114.

Schmidt MF, Bandlow CE, Hassinger TD, Schwab ME, Kater SB (1991) CNS myelin neurite growth inhibitor NI-35 causes a large transient rise in intracellular calcium which precedes growth arrest and collapse of rat DRG growth cones. Soc Neurosci Abstr 17:372.7.

Shaw G, Osborn M, Weber K (1981) Arrangements of neurofilaments, microtubules and microfilament-associated proteins in cultured dorsal root ganglia cells. Eur J Cell Biol 24:20-27.

Silver RA, Lamb AG, Bolsover SR (1989) Elevated cytosolic calcium in the growth cone inhibits neurite elongation in neuroblastoma cells: correlation of behavioral states with cytosolic calcium concentrations. J Neurosci 9:4007-4020.

Silver RA, Lamb AG, Bolsover SR (1990) Calcium hotspots caused by L-channel clustering promote morphological changes in neuronal growth cones. Nature 343:751-754.

Smith SJ (1988) Neuronal cytomechanics: the actin-based motility of growth cones. Science 242:708-715.

Sobue K, Kanda K (1989) Alpha-actins, calspectin (brain spectrin or fodrin), and actin participate in adhesion and movement of growth cones. Neuron 3:311-319.

Sperry RW (1963) Chemoaffinity in the orderly growth of nerve fiber patterns and connections. Proc Natl Acad Sci USA 50:703-710.

Stossel TP, Chaponnier C, Ezzell RM, Hartwig JH, Jammey PA, Kwiatkowski DJ, Lind SE, Smith DB, Southwick FS, Yin HL, Zaner KS (1985) Non muscle actin binding proteins. Annu Rev Cell Biol 1: 353-402.

Suarez-Isla BA, Pelto DJ, Thompson JM, Rapoport SI (1984) Blockers of calcium permeability inhibit neurite extension and formation of neuromuscular synapses in cell culture. Dev Brain Res 14:263-270.

Taghert PH, Bastiani MJ, Ho RK, Goodman CS (1982) Guidance of pioneer growth cones: filopodial contacts and coupling revealed with an antibody to Lucifer yellow. Dev Biol 94:391-399.

Taylor JSH, Roberts A (1983) The early development of the primary sensory neurones in an amphibian embryo: a scanning electron microscope study. J Embryol Exp Morphol 75:49-66.

Tosney KW, Landmesser LT (1985) Growth cone morphology and trajectory in the lumbrosacral region of the chick embryo. J Neurosci 5:2345-2358.

Tsui HCT, Lankford KL, Klein WL (1985) Differentiation of neuronal growth cones: specialization of filopodial tips for adhesive intcractions. Proc Natl Acad Sci USA 82:8256-8260.

Wong RG, Hadley RD, Kater SB, Hauser GC (1981) Neurite outgrowth in molluscan organ and cell cultures: the role of conditioning factor(s). J Neurosci 1:1008-1021.

Wong RG, Barker DL, Kater SB, Bodnar DA (1984) Nerve growthpromoting factor produced in culture media conditioned by specific CNS tissues of the snail Helisoma. Brain Res 292:81-91. 